\title{
Sensitivity of Simulations of Zambian Heavy Rainfall Events to the Atmospheric Boundary Layer Schemes
}

\author{
Mary-Jane M. Bopape ${ }^{1}\left(\mathbb{D}\right.$, David Waitolo ${ }^{2, *}{ }^{\oplus}$, Robert S. Plant ${ }^{3}{ }^{\circledR}$, Elelwani Phaduli ${ }^{1}$, Edson Nkonde ${ }^{2}$, \\ Henry Simfukwe ${ }^{4}$ (D), Stein Mkandawire ${ }^{4}$, Edward Rakate ${ }^{5}$ and Robert Maisha ${ }^{1}$ (D) \\ 1 South African Weather Service, Private Bag X097, Pretoria 0001, South Africa; \\ Mary-Jane.Bopape@weathersa.co.za (M.-J.M.B.); Elelwani.Phaduli@weathersa.co.za (E.P.); \\ Robert.Maisha@weathersa.co.za (R.M.) \\ 2 Zambia Meteorological Department, P.O. Box 50065, Lusaka, Zambia; edson.nkonde@mtc.gov.zm \\ 3 Department of Meteorology, University of Reading, Reading RG6 6ET, UK; r.s.plant@reading.ac.uk \\ 4 Zambia Research and Education Network, School of Education Building First Floor, University of Zambia, \\ West Wing P.O. Box 32379, Lusaka, Zambia; henry.simfukwe@zamren.zm (H.S.); \\ mkandaws@zamren.zm (S.M.) \\ 5 Centre for High Performance Computing, Council for Scientific and Industrial Research, P.O. Box 395, \\ Pretoria 0001, South Africa; ERakate@csir.co.za \\ * Correspondence: david.waitolo@mtc.gov.zm
}

check for updates

Citation: Bopape, M.-J.M.; Waitolo, D.; Plant, R.S.; Phaduli, E.; Nkonde, E.; Simfukwe, H.; Mkandawire, S.; Rakate, E.; Maisha, R. Sensitivity of Simulations of Zambian Heavy Rainfall Events to the Atmospheric Boundary Layer Schemes. Climate 2021, 9, 38. https://doi.org/ $10.3390 /$ cli9020038

Received: 16 December 2020 Accepted: 4 January 2021 Published: 23 February 2021

Publisher's Note: MDPI stays neutral with regard to jurisdictional clai$\mathrm{ms}$ in published maps and institutional affiliations.

Copyright: $(2021$ by the authors. Licensee MDPI, Basel, Switzerland. This article is an open access article distributed under the terms and conditions of the Creative Commons Attribution (CC BY) license (https:// creativecommons.org/licenses/by/ $4.0 /)$.

\begin{abstract}
Weather forecasting relies on the use of numerical weather prediction (NWP) models, whose resolution is informed by the available computational resources. The models resolve large scale processes, while subgrid processes are parametrized. One of the processes that is parametrized is turbulence which is represented in planetary boundary layer (PBL) schemes. In this study, we evaluate the sensitivity of heavy rainfall events over Zambia to four different PBL schemes in the Weather Research and Forecasting (WRF) model using a parent domain with a $9 \mathrm{~km}$ grid length and a $3 \mathrm{~km}$ grid spacing child domain. The four PBL schemes are the Yonsei University (YSU), nonlocal first-order medium-range forecasting (MRF), University of Washington (UW) and Mellor-YamadaNakanishi-Niino (MYNN) schemes. Simulations were done for three case studies of extreme rainfall on 17 December 2016, 21 January 2017 and 17 April 2019. The use of YSU produced the highest rainfall peaks across all three cases; however, it produced performance statistics similar to UW that are higher than those of the two other schemes. These statistics are not maintained when adjusted for random hits, indicating that the extra events are mainly random rather than being skillfully placed. UW simulated the lowest PBL height, while MRF produced the highest PBL height, but this was not matched by the temperature simulation. The YSU and MYNN PBL heights were intermediate at the time of the peak; however, MYNN is associated with a slower decay and higher PBL heights at night. WRF underestimated the maximum temperature during all cases and for all PBL schemes, with a larger bias in the MYNN scheme. We support further use of the YSU scheme, which is the scheme selected for the tropical suite in WRF. The different simulations were in some respects more similar to one another than to the available observations. Satellite rainfall estimates and the ERA5 reanalysis showed different rainfall distributions, which indicates a need for more ground observations to assist with studies like this one.
\end{abstract}

Keywords: flooding; weather forecasting; high performance computing; boundary layer scheme

\section{Introduction}

During the period 1995 to 2015, floods accounted for 47\% of all weather-related disasters, affecting about 2.3 billion people [1]. Of the high impact events discussed in the State of the Climate in Africa 2019 report [2], flooding events were the most reported. Loss of life due to storms is higher in lower-income countries, which account for $89 \%$ of the deaths, despite these countries experiencing just over a quarter of all the storms [1]. 
Adverse impacts of extreme weather and climate events on society can be reduced in the presence of accurate and actionable early warnings, especially for rainfall [3].

In Zambia, the provision of weather and climate services is a mandate of the Zambia Meteorological Department (ZMD) [4]. ZMD was established on 1st January 1967 as a specialized agency with a core responsibility to provide meteorological services to aviation. Due to increases in the severity and frequency of extreme weather events, ZMD is now facing increasing demands for meteorological products and services. Sectors such as agriculture, water, energy and health, along with the Disaster Management Unit, need meteorological information for the purposes of planning, decision-making and policy formulation for mitigation and adaptive strategies against extreme weather events and climate change.

To provide weather forecasts, ZMD runs the Weather Research and Forecasting (WRF) [5] numerical weather prediction (NWP) model, which has been running since December 2019. The grid length used is $14 \mathrm{~km}$. Forecasters also have access to Meteo France ARPÉGE [6] (Action de Recherche Petite Echelle Grande Echelle) and the United Kingdom Met Office (UKMO) Unified Model (UM) [7] outputs through a PUMA 2015 forecaster workstation. In addition forecasters also use output from the Global Forecast System (GFS) [8] and the European Centre for Medium-Range Weather Forecast (ECMWF) integrated forecasting system (IFS) [9] global products via the Internet. Other platforms such as TAMSAT (Tropical Applications of Meteorology using SATellite data and ground-based observations) [10], SWFDP (Severe Weather Forecasting Demonstration Project) [11] and PUMA/MESA (Monitoring for Environment and Security in Africa) 2015 synergie (Eumetcast 1 (https: / / www.eumetsat.int/website/home/Data/DataDelivery/ EUMETCast/index.html) system) are used as well. There are 68 automatic weather stations dotted around the country transmitting real time data every $15 \mathrm{~min}$, of which 10 transmit to the World Meteorological Office (WMO) website [12]. Venäläinen et al. [4] conducted a situational analysis of $\mathrm{ZMD}$ and recommended a number of changes, including an increase in the number of observing stations, a weather radar system and a forecast post-processing system to assist the organization to produce early warnings.

Increases in available computational resources have resulted in an increase in resolution used by NWP models over the last few decades [13]. The ECMWF and UKMO run global NWP models with grid spacings of 9 and $10 \mathrm{~km}$, respectively. The two organizations announced large investments in their high performance computing (HPC) systems of 80 million euro [14] and $£ 1.2$ billion [15] during early 2020. The African continent has largely lagged behind with developments in HPC; however, the situation has started to improve. Through the Southern African Development Community (SADC) Cyber-Infrastructure (CI) Framework, High Performance Computing systems have been deployed in a number of countries within SADC, including Zambia [16].

The HPC system in Zambia is hosted by the University of Zambia at the Zambia Research and Education Network (ZAMREN) HPC facility, and this is the system in use for the current study. The availability of an HPC system in Zambia provides an opportunity for ZMD to conduct NWP research to understand atmospheric processes, and to also determine a suitable configuration for simulating weather and climate in Zambia [17]. Kanno et al. [18] did a 10 year climate simulation with WRF version 3.2 and found the model overestimated rainfall on three sites in the southern province of Zambia. The representations of subgrid processes such as clouds and turbulence are thought to be responsible for much of the uncertainty in weather and climate simulations [19].

Turbulence plays an important role in the development, evolution and diurnal cycle of the planetary boundary layer (PBL) and in the mixing of momentum, heat, moisture and cloud water [20]. Turbulence is produced by a number of atmospheric processes, including buoyant convection, shear forces and cloud-related radiative processes [21]. In most NWP models, turbulence is not resolved, but is parametrized using columnbased PBL schemes [19], within which the PBL height is considered as a key quantity [22]. Qian et al. [23] showed that the choices of PBL and surface layer schemes have large 
impacts on the simulation of surface moisture flux, convection initiation and precipitation over the tropical ocean. There are two main forms of parametrization within PBL schemes: local treatments influence only the model levels immediately adjacent to a given level, and nonlocal treatments are designed to represent the impacts of large eddies such as those in convective PBLs [19].

A number of studies have been conducted in different parts of the globe to assess the performances of different PBL schemes. Jahn and Gallus [24] found the Yonsei University (YSU) [25] and Mellor-Yamada-Nakanishi-Niino (MYNN) [26] PBL schemes to have similar performances when simulating wind speed, but with a warm potential temperature and dry specific humidity bias in YSU compared to MYNN when simulating the Great Plains Low-Level jet. Bélair et al. [27] found a local turbulent kinetic energy (TKE)0based scheme to underestimate the rapid evolution of the PBL in clear moderate and shear-driven convective cases in Montreal. There was more sensitivity to a dry bias in the formulation of the turbulent length scales than to the introduction of a nonlocal term. Cohen et al. [28] compared two local, two non-local and one hybrid local-nonlocal scheme in simulations of United States cold season severe thunderstorms, and concluded that the local schemes produce overly weak vertical mixing and that nonlocal schemes overmix the boundary layer. Comin et al. [29] found nonlocal schemes to perform better in Brazil than local schemes when simulating an extreme rainfall event. When comparing a local, a hybrid local-nonlocal and non-local schemes, Hu et al. [30] found the local scheme to produce larger cold and moist biases than the other two over the South Central United States.

de Lange et al. [31] compared four PBL schemes in WRF over the Highveld of South Africa for June and November 2016 and found the performance to not only be site-specific but variable-specific also. They recommended the use of local schemes for winter; all simulations were better in general compared to November. In this study we compare the performances of four planetary boundary layer schemes in simulating three heavy rainfall events over the southern parts of Zambia. An understanding of the performances of different PBL schemes has implications for operational forecasting, and hence early warnings because the best available scheme has to be established. The next section describes the study area, followed by the simulation design and the data used in the study. The rainfall events are described in Section 4, and simulation results are presented and discussed in Section 5. A summary and conclusions are given in Section 6.

\section{Study Area}

Zambia is a landlocked country that occupies a near central location on the southern African sub-continent between $8^{\circ}$ and $18^{\circ} \mathrm{S}$ latitude, and $22^{\circ}$ and $34^{\circ} \mathrm{E}$ longitude. The Indian Ocean is the nearest sea, and is approximately $800 \mathrm{~km}$ to the east. Both the Indian and Atlantic oceans are important sources of moisture for Zambia [32]. The wet years or wet spells are dominated by low level westerlies, which oppose the mean easterly flow, resulting in a low-level convergence of moisture over the country [32,33]. Zambia's climate is influenced by the equatorial low and the Inter-Tropical Convergence Zone (ITCZ) with its southward and northward movements over Africa in different months of the year [34]. The rains brought by the ITCZ are characterized by thunderstorms, and are occasionally severe, with much lightning [35] and sometimes hail.

Kanno et al. [18] found that the location of the ITCZ resulted in large intra-seasonal variations in three summer seasons that they studied over southern Zambia (from 2007/2008 to 2009/2010). The El Niño Southern Oscillation (ENSO) has also been found to impact the rainfall season of Zambia, with cool ENSO events being associated with increased rainfall [36]. Hachigonta and Reason [33] found a stronger ENSO signal in the southern parts of Zambia than in the north. The climate of the country is also modulated by altitude (the topography is shown in Figure 1). The rainfall distribution is characterized by a downward gradient from north to south, with annual amounts greater than $1200 \mathrm{~mm}$ reported in the north-west and north east of the country, and the lowest amounts in the south-west [34]. 
The northern parts of Zambia receive most of their rainfall from November to March, with a peak between December and January [36].

Many of the economic, cultural and social elements of the country are dominated by the onset and end of the rainy season, and the amount of rain it brings [34]. More than $90 \%$ of the annual rainfall occurs in the rainy season, while $8 \%$ falls in October and April, and $2 \%$ in September and May. Extreme events like droughts [37] and floods are frequent occurrences in Zambia. They have caused crop damage and loss leading to food scarcity and hunger, increases in diseases (malaria, dysentery, cholera, etc.) [38], destruction and damage of infrastructure (houses, buildings, roads, bridges) [39], reduced charcoal business, decline in fish catches and loss of life (humans and livestock). Thurlow and Diao [40] indicated that climate variability reduced the gross domestic product of Zambia by about $4 \%$ and increased the number of people living below the poverty line by $2 \%$ over a ten year period.

\section{Model domains and height above sea level}
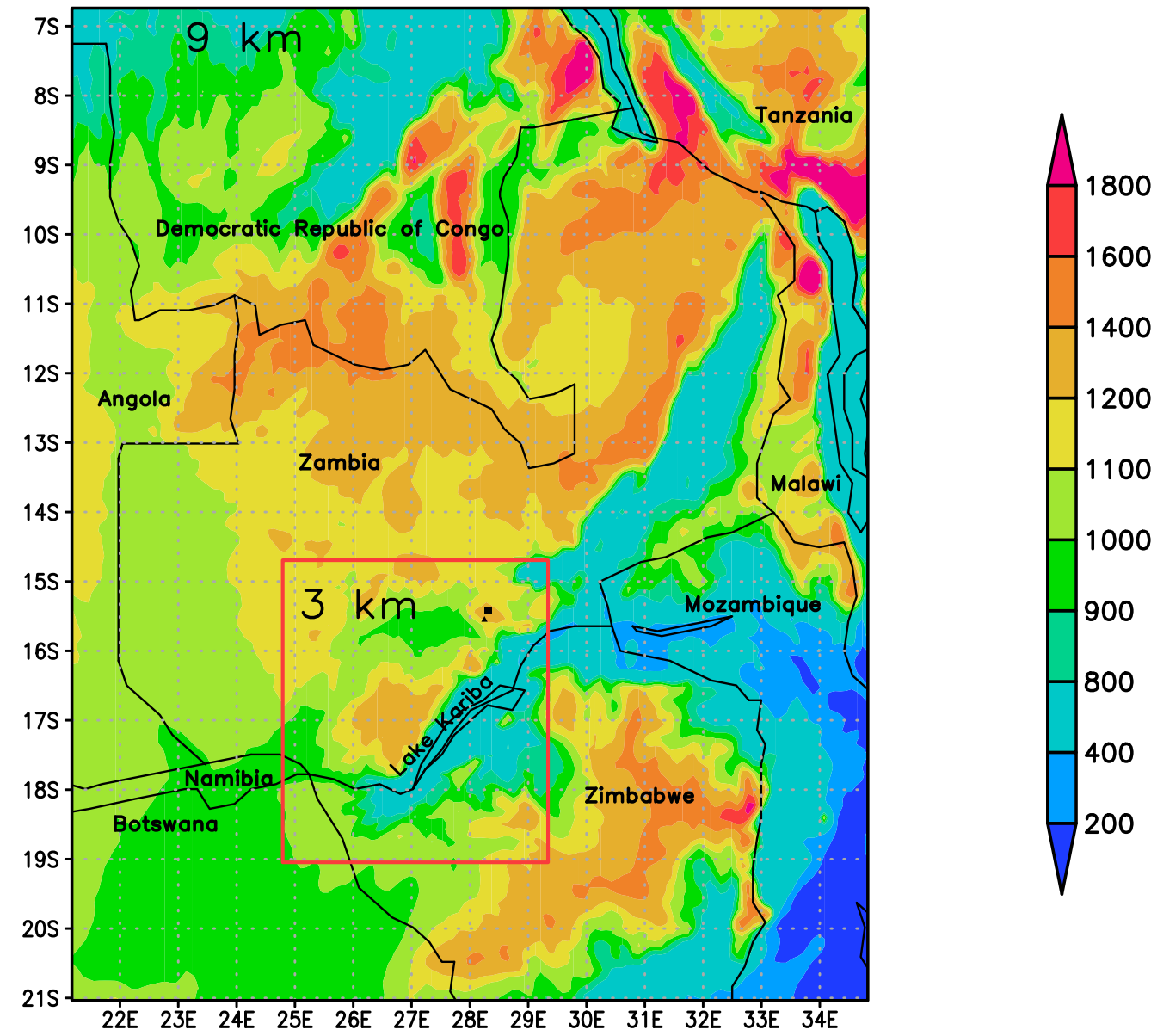

Figure 1. The outer domain of the $9 \mathrm{~km}$ grid length model and the $3 \mathrm{~km}$ grid length child domain (red box) with country names and location of Lake Kariba indicated. The colors indicate topography in $\mathrm{m}$.

\section{Model, Data and Simulations}

The Advanced Research WRF (ARW) model version 4.1.2 [5] was used in this study, with four different boundary layer schemes as described below. WRF was chosen because it is an open source community model, with many physics choices, and can be used for operational forecasting without any associated license fee. The model can be used for simulating processes with scales ranging from turbulent eddies to global systems. It is fully compressible, with a nonhydrostatic option that allows convective-scale [41] simulations 
to be conducted. A wide range of choices can be made for the physical parametrizations. Two physics suites are provided [42]: the CONUS suite, which is deemed suitable for the Continental United States, and a tropical suite, which has been found to work well for the tropical belt [43]. The tropical suite was selected for this study because of the location of Zambia in the lower latitudes. It uses the rapid radiative transfer model (RRTM) for both short and long wave radiation [44], the WRF Single Moment 6-class microphysical scheme (WSM6) [45] and the new Tiedtke cumulus scheme [46-48].

\subsection{Boundary Layer Schemes}

In this study we tested the performances of four PBL schemes in simulating heavy rainfall events over Zambia. We recognize that the $3 \mathrm{~km}$ grid length used in the study approaches the gray-zone for the convective PBL when at its peak height (Section 5.3). However, the aim of the study was to investigate different forms of column-based PBL schemes in a real NWP context. Two of the schemes calculate a mixing length scale based on turbulent kinetic energy (TKE), while the other two include a nonlocal contribution to the turbulent fluxes to represent the mixing from large eddies in the daytime CBL [49]. Shallow cumulus convection is also considered in two of the schemes. The four schemes used were:

- The Mellor-Yamada-Nakanishi-Niino (MYNN) PBL scheme [26]: this scheme is the improved Mellor-Yamada scheme based on TKE.

- The Community Atmosphere Model (CAM) University of Washington (UW) Moist Turbulence scheme [50]: this scheme is TKE based and also considers shallow convection.

- $\quad$ The Medium Range Forecast (MRF) Model PBL scheme [51]: this scheme includes a non-local term.

- The Yonsei University (YSU) PBL scheme [25]: this scheme includes a diagnostic non-local term, and considers shallow convection, along with a top-down turbulence contribution associated with cloud-top radiative cooling.

The schemes are further summarized in Table 1 for a quick reference on differences amongst the four selected for this study.

Table 1. A summary of the schemes used.

\begin{tabular}{cccc}
\hline Scheme & Non-Local & TKE-Based & Shallow Convection \\
\hline YSU & Yes & No & Yes \\
UW & No & Yes & Yes \\
MRF & Yes & No & No \\
MYNN & No & Yes & No \\
\hline
\end{tabular}

\subsection{Simulation Design}

A one-way nesting procedure was applied with WRF forced with the GFS data [8], which provide time-dependent lateral boundary conditions (LBCs) for the outer domain, updated every three hours of simulation time. The presentation of results focuses on WRF simulations run from 16 April 2019 at 00:00 UTC until 18 April 2019 00:00 UTC. This event was selected because it was associated with the highest rainfall amount recorded in $24 \mathrm{~h}$ in 2019 of $92.6 \mathrm{~mm}$ at Mount Makulu agromet weather station. Two further events were also considered. A thirty hour simulation was done for 21 January 2017, on which $91 \mathrm{~mm}$ and $92.6 \mathrm{~mm}$ of rainfall were recorded within a $24 \mathrm{~h}$ period at the Mount Makulu agromet and Lusaka city airport weather stations respectively. Additionally, selected was 17 December 2016, where $106 \mathrm{~mm}$ was reported within $24 \mathrm{~h}$ at Lusaka city airport weather station. The location of Mount Makulu agromet station is indicated by a closed triangle, and the Lusaka city station by a closed square in Figure 1, and they are at elevations of $1213 \mathrm{~m}$ and $1252 \mathrm{~m}$, respectively. These three cases represent the highest recorded rainfall amounts in the period from 11 May 2016 (when the number of vertical levels in the GFS driving data increased 
from 27 to 32) to October 2020. The next highest amount is $73.2 \mathrm{~mm}$ which was recorded in Livingstone on 7 February 2018; however, only cases with rainfall amounts greater than $90 \mathrm{~mm}$ in the southern parts of Zambia were considered in this study.

A nesting procedure was employed, with a $9 \mathrm{~km}$ grid length model domain nested directly within GFS, and a child nest using a grid length of $3 \mathrm{~km}$. The $9 \mathrm{~km}$ parent domain spans $21.2^{\circ}-34.82^{\circ} \mathrm{E}$ and $18.97^{\circ}-6.88^{\circ} \mathrm{S}$, while the $3 \mathrm{~km}$ domain covers $24.79^{\circ}-29.34^{\circ} \mathrm{E}$ and $19.05^{\circ}-14.69^{\circ} \mathrm{S}$. Figure 1 shows the full $9 \mathrm{~km}$ domain, with the red rectangle showing the smaller $3 \mathrm{~km}$ domain. The new Tiedtke scheme [46-48] for deep cumulus convection is used for the $9 \mathrm{~km}$ model domain, but is switched off within the child domain, in line with typical practice for convection-permitting resolutions (e.g., [41,52-54]).

\subsection{Datasets}

Quantitative precipitation estimates (QPE) from two satellite products were used to study the spatial rainfall distribution. The first QPE used is TAMSAT developed at the University of Reading [10,55]. TAMSAT provides daily rainfall estimates for all of Africa on a $4 \mathrm{~km}$ grid. The second QPE is the $30 \mathrm{~min}$ interval Integrated Multi-satellitE Retrievals for Global Precipitation Measurement (GPM) (IMERG) rainfall calibrated with ground observations [56]. This dataset will be referred to as IMERG for the rest of the paper.

ERA5 is the latest climate reanalysis from ECMWF [57] and is used here to study other variables, including temperature and winds. ERA 5 combines vast amounts of historical observations into global estimates using the IFS and data assimilation systems. Two ERA5 reanalysis products were used: the land surface variables with a grid spacing of $0.1^{\circ}$, referred to as ERA5_Land henceforth, and $0.25^{\circ}$ data which shows the synoptic circulation (ERA5 henceforth). The temporal interval provided by both IMERG and ERA5 makes it possible for us to study the timing of rainfall, whereas TAMSAT is only available at daily intervals.

Ground observations for maximum and minimum temperature, and twenty-four hour rainfall from $Z M D$ were also used to verify the model. The number of reporting stations differs per event and per variable. For 17 December 2016, 17 stations were used for minimum temperature, 15 for maximum temperature and 18 for rainfall. On 21 January 2017, 16 stations reported minimum temperature, 17 reported maximum temperature and 18 reported $24 \mathrm{~h}$ rainfall. For the last case of 17 April 2019, 13 stations reported both minimum and maximum temperature, and 14 reported twenty-four hour rainfall.

\subsection{Verification Scores}

A number of performance measures were calculated for all three case studies using the Developmental Testbed Centre (DTC) Model Evaluation Tools (MET) software version 8.1.2. Verification statistics are presented for rainfall simulations for the $9 \mathrm{~km}$ model, using the observational IMERG data. The model output was regridded onto the IMERG grid using the Grid Analysis and Display System (GrADS) regrid function. The Method for Object-Based Diagnostic Evaluation (MODE) tool [58-60] within MET was used. MODE was designed to avoid the "double penalty" problem associated with traditional verification measures by using matched areas or object pairs to calculate the performance statistics. Object-based verification statistics are especially useful for convective scale models which usually struggle with capturing exact rainfall locations [52]. A number of performance statistics are calculated based on the contingency Table 2 and these are listed below in a similar way to Beusch et al. [61].

Table 2. Contingency table for calculating the skill scores.

\begin{tabular}{cccc}
\hline & & \multicolumn{2}{c}{ Observations } \\
\hline \multirow{2}{*}{ Forecast } & & Yes & No \\
& Yes & hits $(\mathrm{H})$ & false alarms $(\mathrm{F})$ \\
& No & misses $(\mathrm{M})$ & correct rejects $(\mathrm{R})$ \\
\hline
\end{tabular}


The Probability of detecting yes (PODY) indicates the proportion of correctly predicted events from total observed events. PODY ranges between 0 and 1 , with 1 being the perfect score, and it is given by:

$$
\text { PODY }=\frac{H}{H+M}
$$

The false alarm ratio (FAR) indicates the proportion of false alarms to all forecasts, it ranges from 0 to 1 , with 0 being a perfect score. It is defined as:

$$
F A R=\frac{F}{F+H} .
$$

The critical success index (CSI) indicates proportion of hits in all predicted and missed events. It ranges between 0 and 1, with 1 being a perfect score and is given by:

$$
C S I=\frac{H}{H+F+M} .
$$

The Gilbert skill score (GSS) is the CSI adjusted to account for random chance, and has a perfect score of 1 :

$$
G S S=\frac{H-H r}{H+F+M-H r},
$$

where $\mathrm{Hr}$ denotes the hit rate that would occur due to chance,

$$
H r=\frac{(H+M)(H+F)}{(H+M+F+R)} .
$$

The Hanssen-Kuiper discriminant (HK) indicates the ability of the forecast to classify events and non-events ( 0 indicates no skill and 1, a perfect score):

$$
H K=\frac{H}{H+M}-\frac{F}{F+R} .
$$

The Hiedke skill score (HSS) gives the proportion of correct predictions after removing predictions that are correct due to random chance. A perfect score is given by a value of 1 , while 0 indicates no skill, and it is defined by:

$$
H S S=\frac{(H+R)-(H r+R r)}{(H+M+F+R)-(H r+R r)}
$$

where $R r$ denotes the rejection rate due to chance,

$$
R r=\frac{(F+R)(M+R)}{(H+M+F+R)} .
$$

Performance verification statistics were also calculated using ZMD maximum and minimum temperature observations for all the case studies, and PBL schemes. The mean error (ME) and root mean square error (RMSE) were calculated using simulations interpolated to the available stations using the following equations:

$$
\begin{gathered}
M E=\bar{F}-\bar{O} \\
R M S E=\sqrt{\frac{1}{N} \sum_{i=1}^{n}\left(F_{i}-O_{i}\right)^{2}}
\end{gathered}
$$

where $F$ represents the simulations, $O$ the observations and $N$ the total number of reporting weather stations. 


\section{Event Descriptions}

The ERA5 mean sea level pressure (MSLP) overlaid with $10 \mathrm{~m}$ winds for all three cases is shown in Figure 2. For the April 2019 case, the plot is made both for 16 April (Figure 2c) and 17 April (Figure 2d). The MSLP plots show that the Atlantic Ocean high (AOH) was ridging over the eastern parts of the subcontinent during all the three cases. The system is associated with an onshore flow over the eastern coastline of the subcontinent whose northward extension differs amongst the events. The onshore winds transport moist air from the Indian ocean over land. The pressure is highest in the April 2019 event, and the onshore winds on 17 April extend across the whole eastern coastline. Areas of lower pressure can be seen over Namibia that extend into Botswana and South Africa during the 17 December 2016 and the 21 January 2017 events.

a) ERA5 SLP \& Winds on 17 Dec 2016

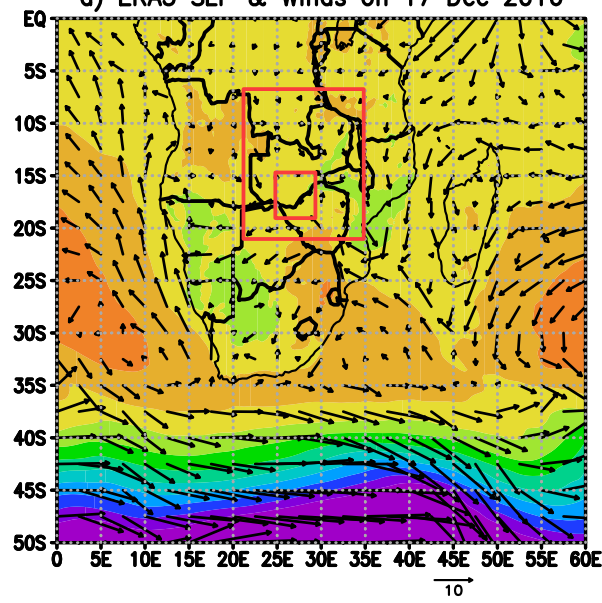

c) ERA5 SLP \& Winds on 16 Apr 2019

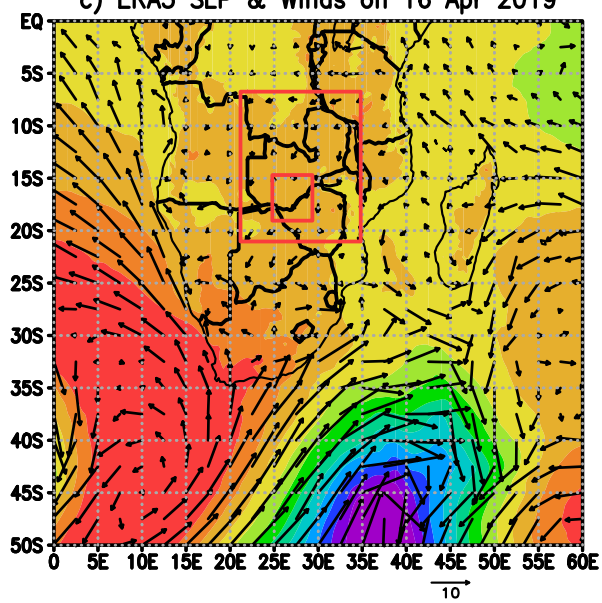

b) ERA5 SLP \& Winds on 21 Jan 2017

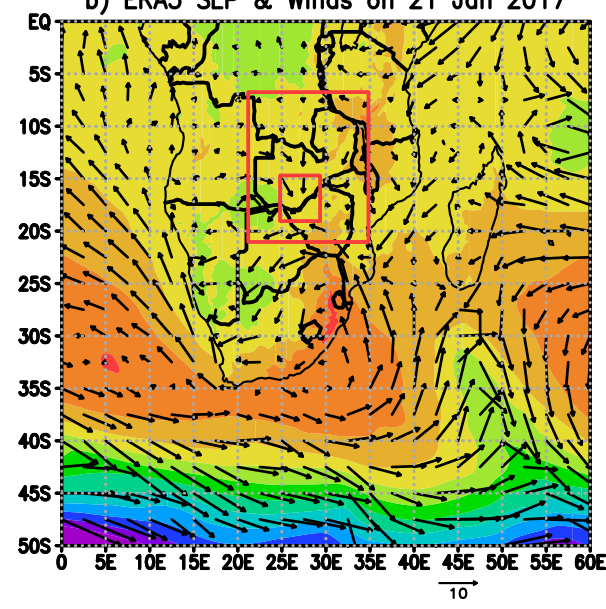

d) ERA5 SLP \& Winds on 17 Apr 2019

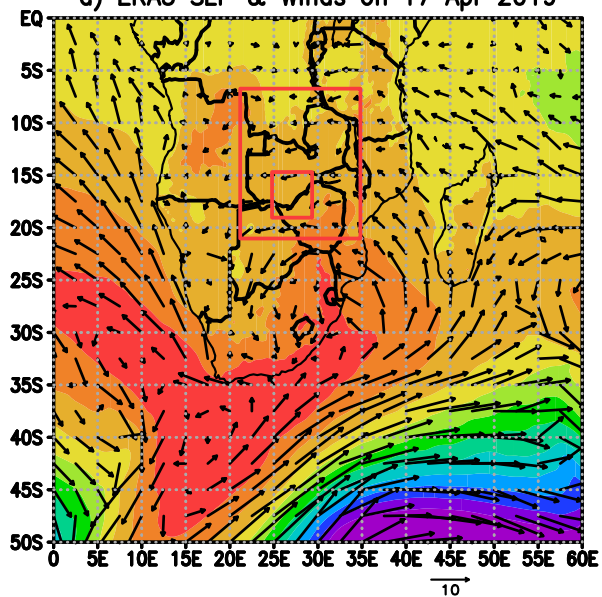

Figure 2. ERA5 mean sea level pressure (colors, hPa) overlaid with $10 \mathrm{~m}$ wind arrows at 09h00 UTC on (a) 17 December 2016, (b) 21 January 2017, (c) 16 and (d) 17 April 2019. A scale for the wind arrows is provided by the $10 \mathrm{~ms}^{-1}$ arrow below the panels.

On 16 April 2019, the $\mathrm{AOH}$ was ridging along the southern parts of the continent and there was not much onshore flow along the eastern coastal region. The heavy rainfall was observed on 17 April, when strong onshore flow had developed from the Indian ocean. Hachigonta and Reason [33] found wet spells over Zambia to be associated with an Angolan low which transports moisture from the tropical south-east Atlantic Ocean and with low level westerly anomalies. Libanda et al. [32] also found low level westerly flow to contribute towards anomalous wet seasons in Zambia. However, these three events demonstrate that the Indian ocean can also be an important moisture source for wet 
spells in Zambia. The upper air synoptic conditions were also considered and nothing of significant note was observed for these cases near or over Zambia.

WRF is nested within the GFS, which provides the interpolated initial conditions and the lateral boundary conditions. To determine whether GFS captured the general synoptic circulation of the three events, the MSLP and $10 \mathrm{~m}$ winds were also plotted for GFS (Figure 3). GFS captured the ridging AOH for all three cases, and the higher pressures of the April 2019 case. The GFS also captured the difference in wind patterns along the east coast on 16 and 17 April, with clearer onshore flow on 17 April. The simulated pressure over land, however, is somewhat lower in general compared to ERA5. The Angola low is clearer in the GFS than in the ERA5, with the lowest pressure over land.

a) GFS SLP \& Winds on 17 Dec 2016

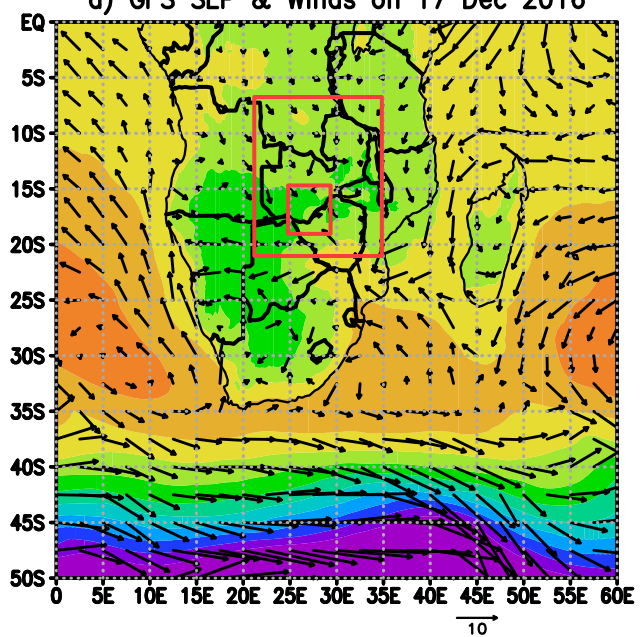

c) GFS SLP \& Winds on 16 Apr 2019

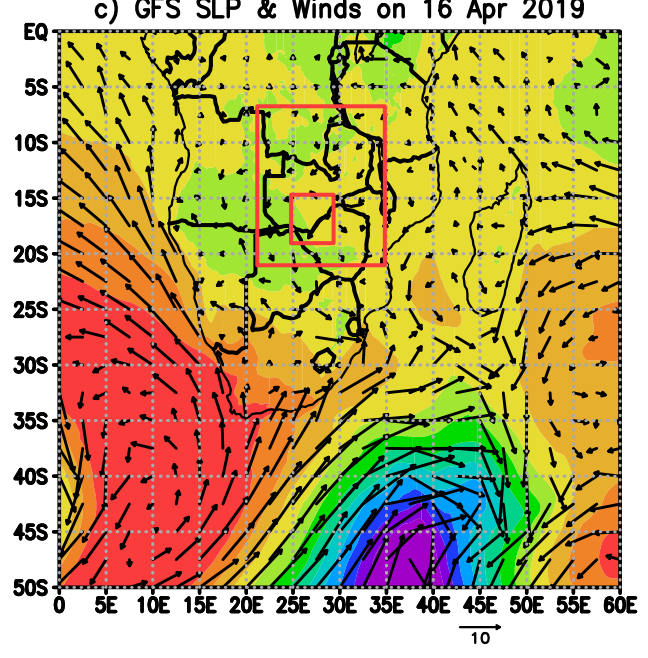

b) GFS SLP \& Winds on 21 Jan 2017

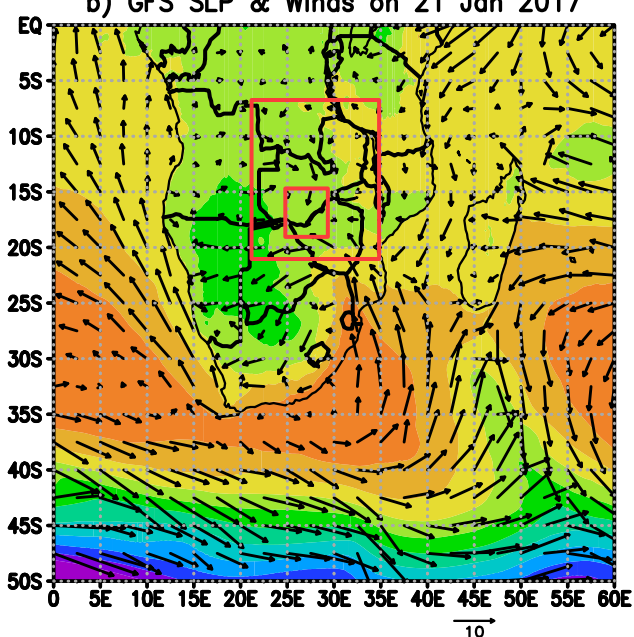

d) GFS SLP \& Winds on 17 Apr 2019

1002

999

996

993

990

Figure 3. As in Figure 2 but for the GFS driving data.

A number of studies have compared the performance of GFS and the ECMWF IFS (on which ERA5 is based) in simulating tropical convection (e.g., [62,63]). Both systems have been found to perform well for short lead times, especially up to $24 \mathrm{~h}$ ahead. Beyond this time, the IFS was found to outperform the GFS in general, while the precipitation from both modelling systems was considered to be not useful beyond 4 days based on a number of metrics. Although there are differences in pressure over land, we conclude that the GFS was able to capture the major features responsible for moisture transport over Zambia. This implies that WRF was forced with suitable synoptic fields. It should be noted that the GFS data were selected for the study because the data is readily available and open, and is used to force NWP models in operational mode. 
The African continent is characterized by sparse observations which make it difficult to evaluate the performance of models [2]. To allow for a comparison of the spatial distribution of rainfall, several observation products are compared, because the ground observations are too limited to provide a useful distribution of rainfall. In Figure 4 we show rainfall over Zambia for the three cases from TAMSAT and IMERG which provide satellite rainfall estimates calibrated with ground observations. TAMSAT has higher resolution with a grid length of $4 \mathrm{~km}$, while IMERG has a grid length of $0.1^{\circ}$. In general the pattern of the area covered by rainfall is similar in the two products, for the three events. The spatial distribution covers most of Zambia on 17 December 2016, but excludes most of the north eastern part of the country on 21 January 2017. On 17 April 2019 the rainfall area is smaller, with most of the rainfall occurring in the north western parts of Zambia. TAMSAT rainfall does not exceed $40 \mathrm{~mm}$ anywhere over Zambia for the 17 December 2016 and 21 January 2017 case studies, although some larger rainfall amounts are reported by this product for the 17 April 2019 event. A comparison of the largest amounts on 17 December 2016 and 21 January 2017 indicates that TAMSAT underestimated the observed rainfall for these two events, given that over $90 \mathrm{~mm}$ was reported by at least one station in the southern parts of Zambia as indicated in the station rainfall shown in Figures 5a and 6a.

a) IMERG $\operatorname{rain}(\mathrm{mm}) 17$ Dec 2016

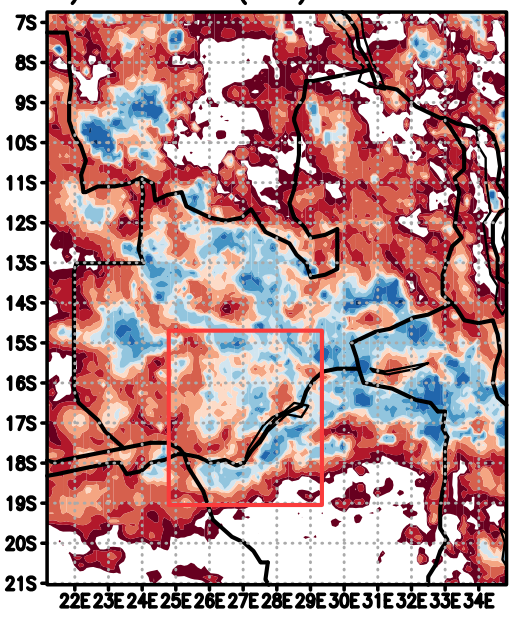

b) TAMSAT rain(mm) 17 Dec 2016

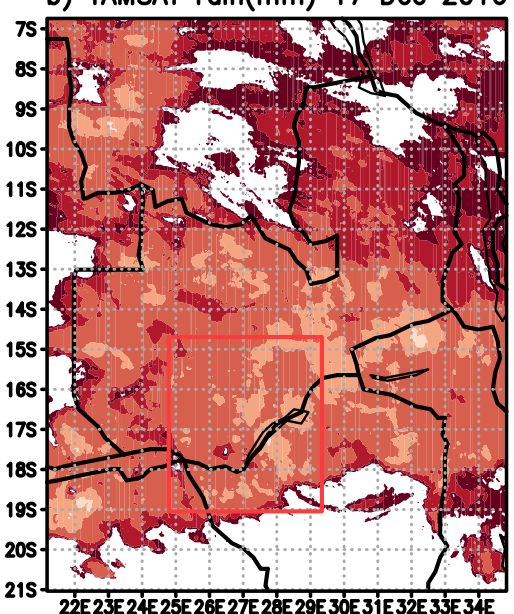

c) IMERG rain(mm) 21 Jan 2017

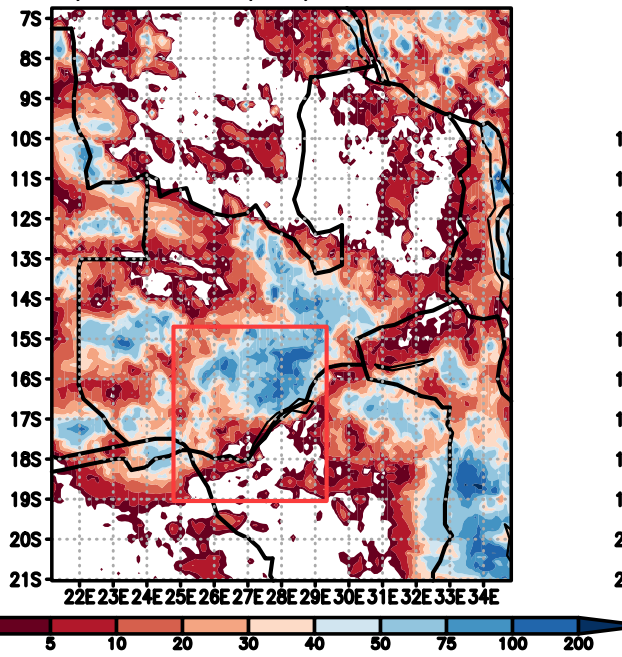

d) TAMSAT rain(mm) 21 Jan 2017

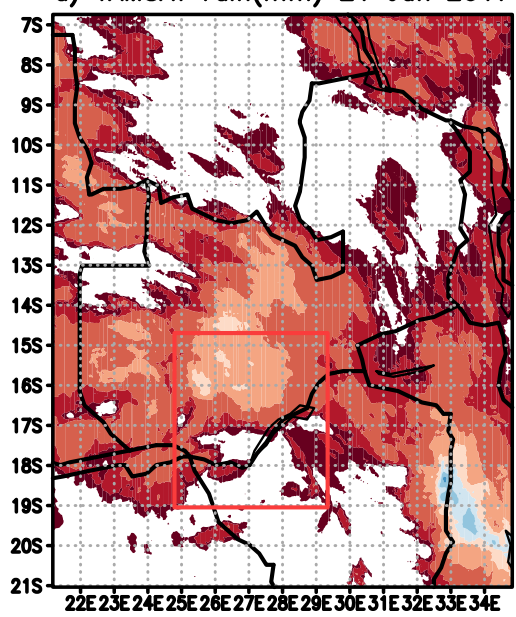

e) IMERG $\operatorname{rain}(\mathrm{mm}) 17$ Apr 2019

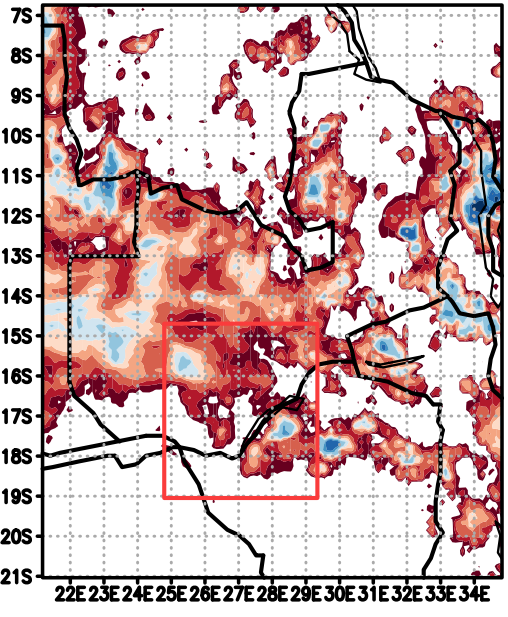

f) TAMSAT rain(mm) 17 Apr 2019

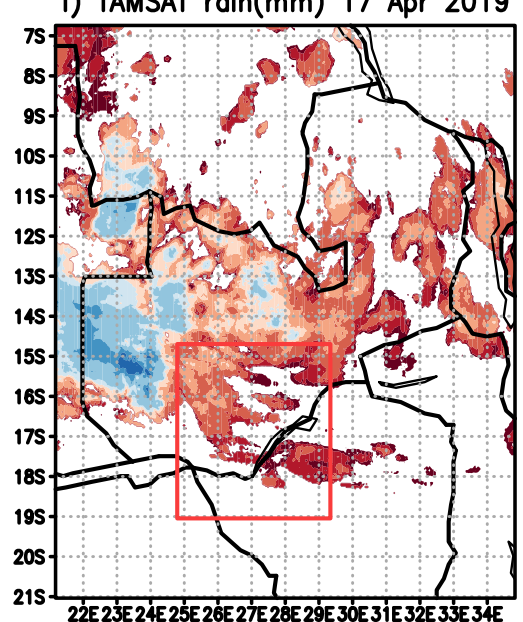

Figure 4. IMERG (a,c,e) and TAMSAT (b,d,f) twenty-four hour rainfall (mm) on 17 December 2016 (a,b), on 21 January 2012 (c,d) and on 17 April 2019 (e,f). 


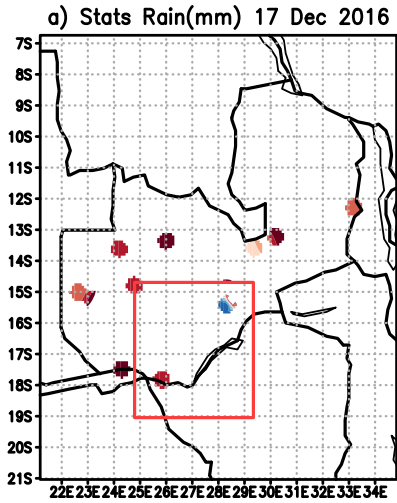

b) YSU Rain 17 Dec 2016

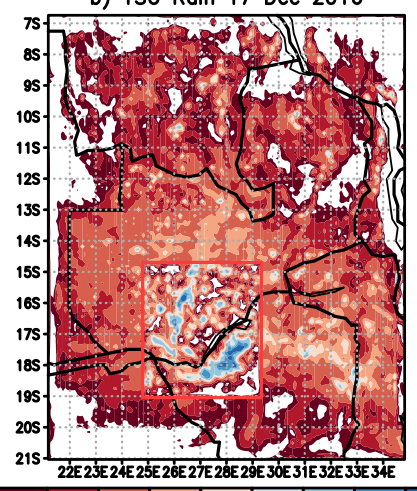

e) MRF Rain 17 Dec 2016

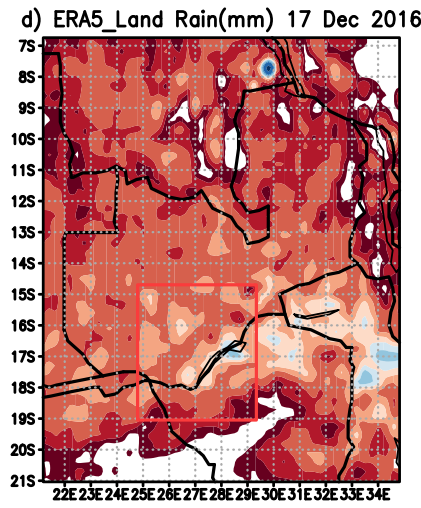

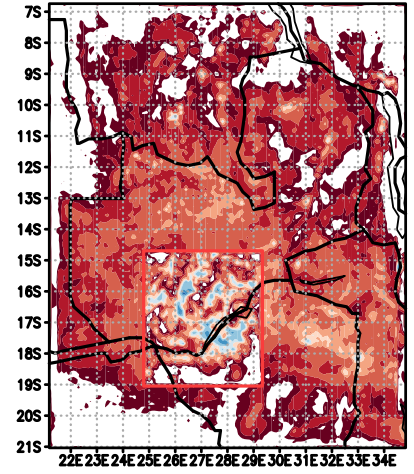

c) UW Rain 17 Dec 2016

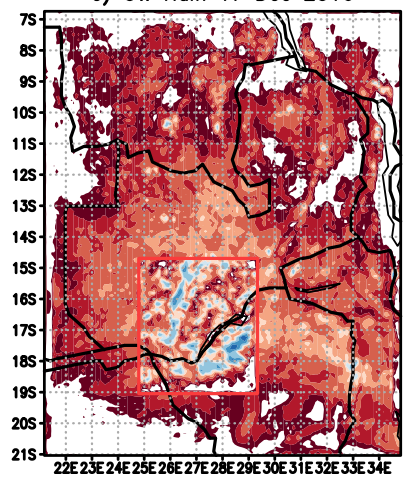

f) MYNN Rain 17 Dec 2016

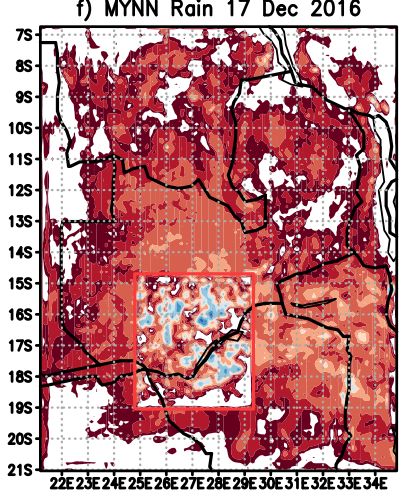

Figure 5. Twenty-four hour rainfall (mm) on 17 December 2016 from (a) ZMD station data, (d) ERA5_Land, along with that from WRF simulations with the (b) YSU, (c) UW, (e) MRF and (f) MYNN PBL schemes.

a) Stats Rain(mm) 21 Jan 2017
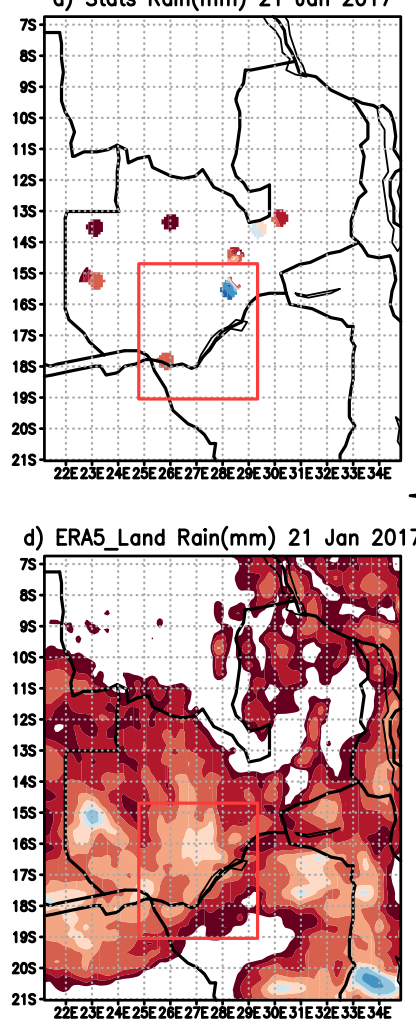

b) YSU Rain 21 Jan 2017

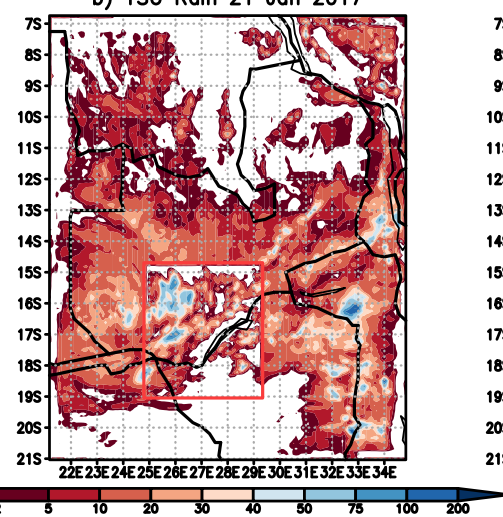

e) MRF Rain 21 Jan 2017

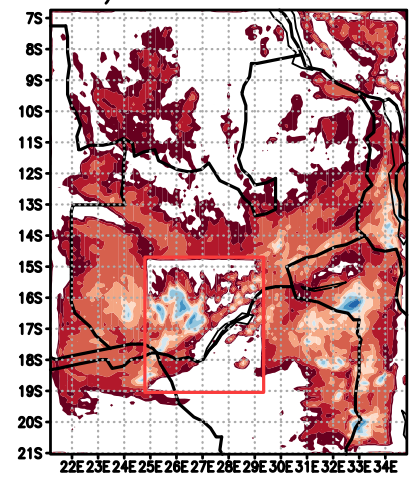

c) UW Rain 21 Jan 2017

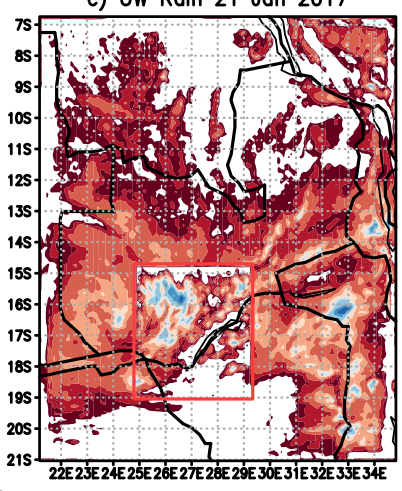

f) MYNN Rain 21 Jan 2017

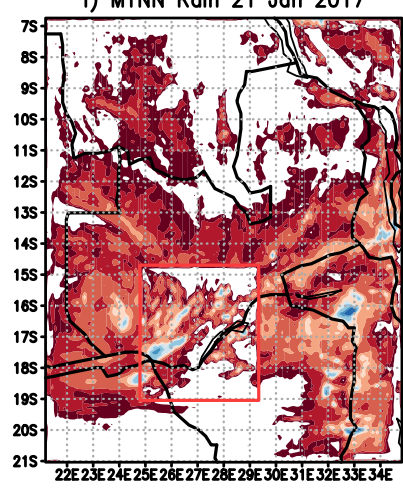

Figure 6. Twenty-four hour rainfall (mm) on 21 January 2017 from (a) ZMD station data and (d) ERA5_Land, along with that from Weather Research and Forecasting (WRF) simulations with the (b) YSU, (c) UW, (e) MRF and (f) MYNN PBL schemes. 
The ERA5_Land reanalysis data are shown in Figures $5 d$ to $7 d$ for the three cases in their order of occurrence. The ERA5_Land pattern differences for the three case studies are also aligned with those observed by IMERG and TAMSAT. The rainfall amounts, however, are generally smaller compared to IMERG. In previous heavy rainfall studies with strong synoptic forcing from an ex-tropical cyclone over Botswana [64] and a cut-off low [65] over Namibia [66], TAMSAT was found to severely underestimate rainfall compared to ERA5 and IMERG. Thorne et al. [67] found TAMSAT to perform well over plateau, but to underestimate rainfall in mountainous regions. Syama et al. [68] found TAMSAT to perform worse than other products in estimating winter rainfall over southern Africa but to perform well with summer rainfall, and they concluded that TAMSAT is geared for ITCZ-related convective rainfall. Beck et al. [69] found ERA5 to outperform IMERG over complex topography, while IMERG performed better in regions dominated by convective storms over the United States. In this study the ERA 5 rainfall with a $0.25^{\circ}$ grid length was also analysed and found to be closely aligned to the ERA5_Land. Given the large amount of rainfall recorded by ground observations we conclude that TAMSAT (for two cases), ERA5 and ERA5_Land underestimated the rainfall in these extreme cases, and we therefore use IMERG to calculate the verification statistics described in Section 3.4.

a) Stats Rain(mm) 17 Apr 2019

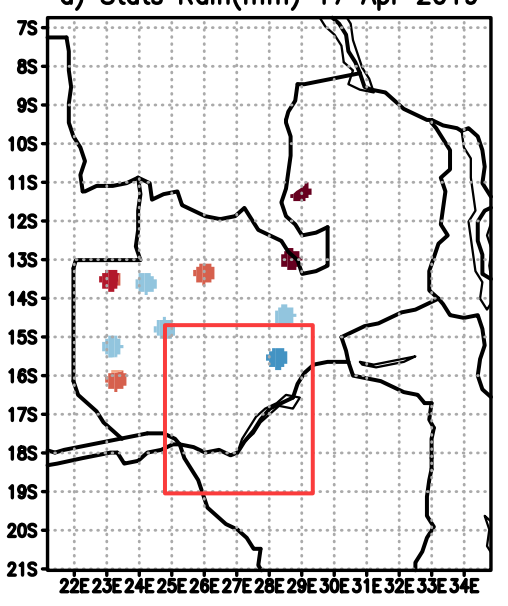

d) ERA5_Land Rain(mm) 17 April 2019

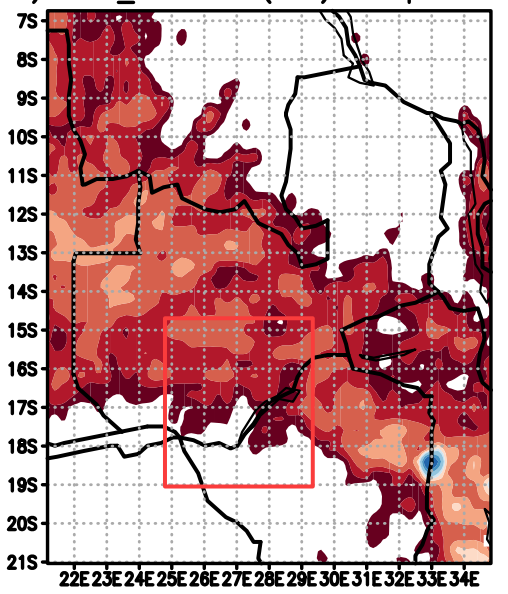

b) YSU Rain 17 Apr $9 \mathrm{~km}$

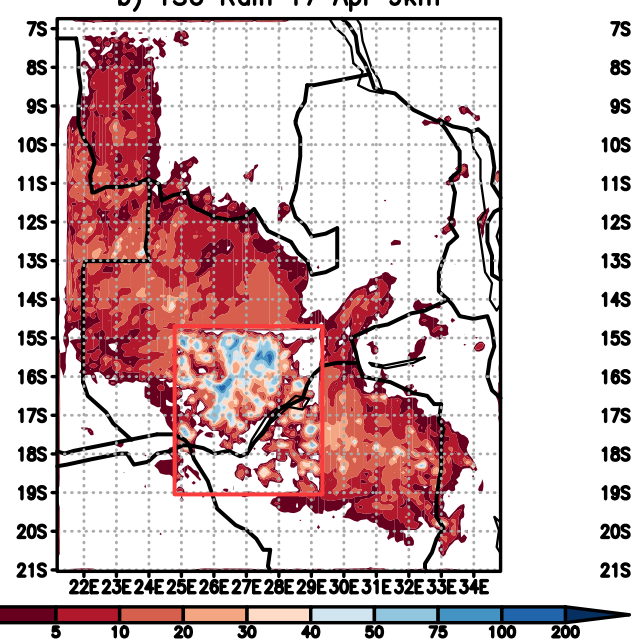

e) MRF Rain $17 \mathrm{Apr} 9 \mathrm{~km}$

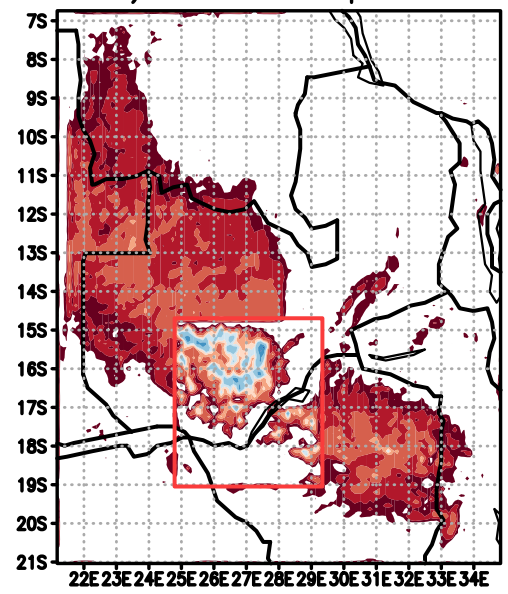

c) UW Rain 17 Apr 9km

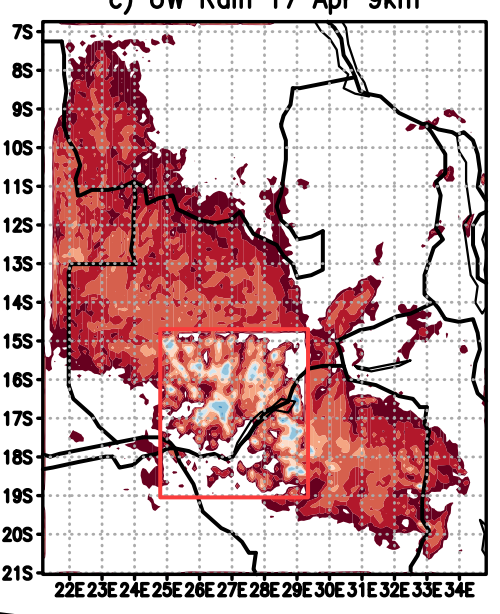

f) MYNN Rain 17 Apr 9km

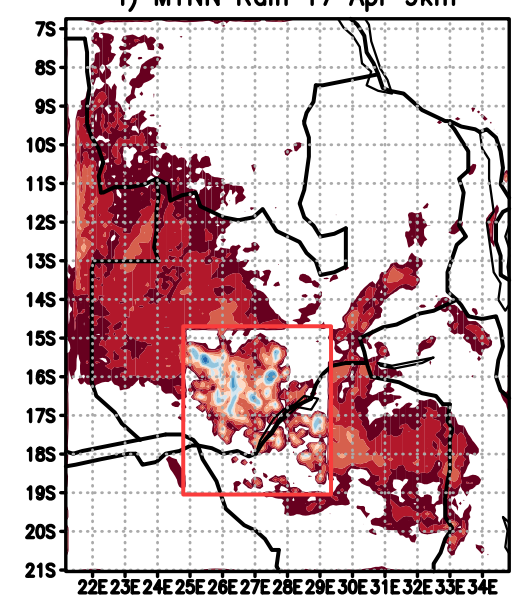

Figure 7. Twenty-four hour rainfall (mm) on 21 January 2017 from (a) ZMD station data and (d) ERA5_Land, along with that from WRF simulations with the (b) YSU, (c) UW, (e) MRF and (f) MYNN PBL schemes. 


\section{Comparison of Simulations}

\subsection{Twenty-Four Rainfall Eyeball Comparisons}

The current section focuses on a comparison of WRF twenty-four hour rainfall amounts using different boundary layer schemes. Figure 5 shows the simulated rainfall with the four boundary layer schemes on 17 December 2016, alongside the station rainfall and ERA5_Land product. IMERG indicates rainfall over most of the domain, with the exception of the extreme southern parts of the domain, with some areas exceeding $60 \mathrm{~mm}$ over the central parts (Figure 4a). Rainfall of over $60 \mathrm{~mm}$ is simulated in parts of the inner $3 \mathrm{~km}$ domain. The ERA5_Land amounts are mainly lower, with an area of higher rainfall along Lake Kariba (Figure 5d). All WRF configurations captured the general rainfall pattern, but the larger rainfall amounts were not captured outside the $3 \mathrm{~km}$ domain. The different simulations appear more similar to one another than they are to IMERG and ERA5_Land. In a recent comparison of different microphysical schemes in WRF, Molongwane et al. [64] also found the simulations to look more similar to one another than to observations. YSU and UW simulated rainfall aligned parallel with the southern border of Zambia and hence Lake Kariba, as also found in IMERG. These two schemes include a component that represents the impact of shallow convection on mixing. The alignment is less clear with MRF and MYNN.

Figure 6 is the same as Figure 5, but for 21 January 2017. The rainfall spatial coverage is smaller than for 17 December 2016, and IMERG again (Figure 4c) indicates areas with rainfall amounts exceeding $70 \mathrm{~mm}$. Most of the north eastern part of the inner domain has rainfall amounts exceeding $40 \mathrm{~mm}$. This is not found in the ERA5_Land; however, and we note that this cannot be attributed to resolution differences as the two datasets are of similar resolution. The different WRF configurations did not capture the regions with higher rainfall outside the $3 \mathrm{~km}$ domain, and they all produced a rainfall gap on the northern boundary of the inner domain. Recalling the northerly flow across this boundary (Figures $2 \mathrm{~b}$ and $3 \mathrm{~b}$ ), the gap is likely a spin-up effect caused by adjustment from the $9 \mathrm{~km}$ configuration with parametrized convection to the $3 \mathrm{~km}$ convection-permitting configuration. YSU, UW and MRF simulated the most rainfall in the north-western part of the inner domain, whereas MYNN simulated a smaller area of higher rainfall further to the south.

The total rainfall for 17 April 2019 is shown in Figure 7. TAMSAT estimated higher rainfall amounts for this case with the largest rainfall estimates to the north-west of inner domain (Figure 4f), while IMERG (Figure 4) presented larger amounts to the east of the $9 \mathrm{~km}$ domain. The ERA5_Land product (Figure 7d) indicated a continuous area of rainfall over the whole northern portion of the inner domain. It also indicated slightly more rainfall coverage to the north and north west of the inner domain (in agreement with TAMSAT), although the ERA5_Land rainfall amounts are lower than TAMSAT. There is a very clear qualitative difference in the WRF simulated rainfall between the $3 \mathrm{~km}$ and $9 \mathrm{~km}$ model domains. This difference reflects the different treatments of deep convection. In particular, various small areas are simulated within the $3 \mathrm{~km}$ domain where rainfall exceeds $50 \mathrm{~mm}$. Similarly to other cases, there is a closer match between the different model configurations than there is to the observations or between the different observations. YSU and MRF produced the highest amount of rainfall in the north-west of the inner domain, and both these schemes are non-local. The UW scheme is associated with the smallest peak intensities, although it does produce some values greater than $50 \mathrm{~mm}$, somewhat scattered across the inner domain. It may be noted that YSU is the selected scheme for the tropical suite [42].

\subsection{Hourly Rainfall Eyeball Comparisons}

In order to understand how the PBL schemes interact with the simulated convection, the current and next two subsections present a closer investigation of the 17 April 2019 case, the simulation for which starts on 16 April 2019. The area maximum hourly rainfall within the $3 \mathrm{~km}$ inner domain is shown for the different WRF configurations in Figure 8a, with 
corresponding results from IMERG and ERA5. As already discussed, ERA5 underestimated the rainfall in this event, and this is apparent also in the hourly maximum plot. IMERG estimated heavy rainfall outside the area of the inner domain and it produced lower maximum values within that area. All of the WRF configurations simulated large maxima on 17 April compared to the previous day. The simulated maxima are quite similar for the first $9 \mathrm{~h}$ of the runs, but diverge later. The two non-local schemes (i.e., YSU and MRF) are associated with the largest hourly rainfall peaks, although these were not simulated at the same time. The MRF peak occurred at 1000 UTC on 17 April, and beyond that time MRF typically simulated lower maxima than the other schemes.

a) Areal maximum hourly rainfall

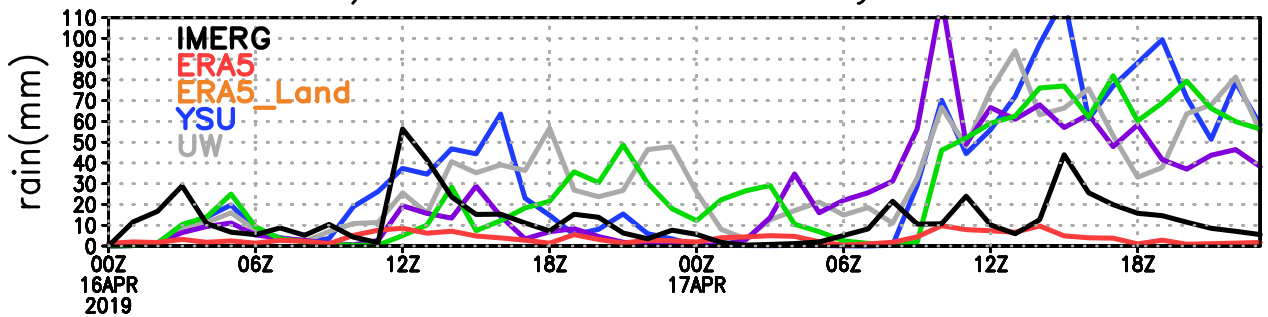

b) Areal minimum hourly temperature

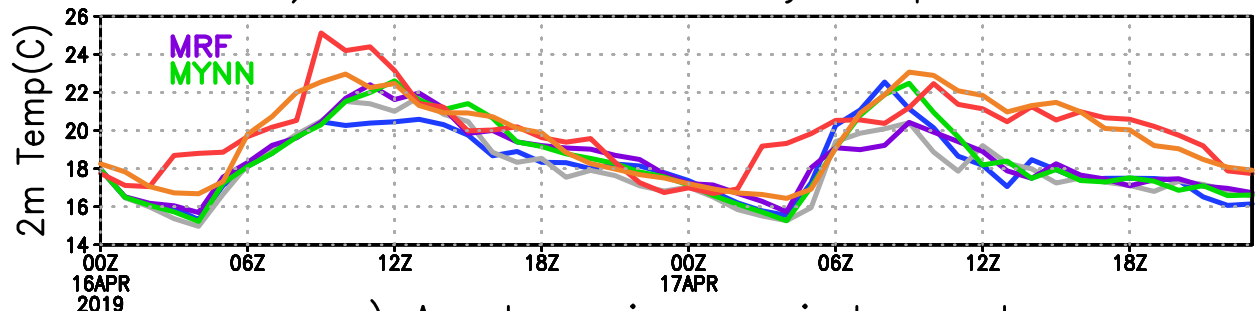

c) Areal maximum wind speed

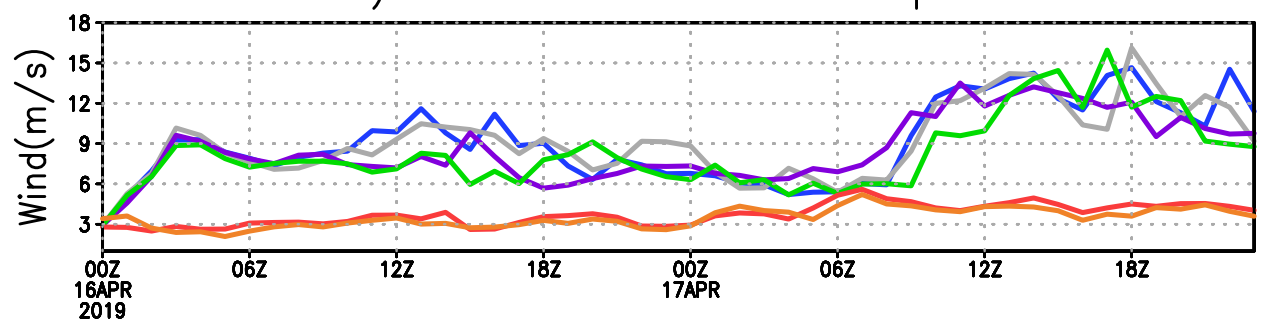

Figure 8. Timeseries for the $3 \mathrm{~km}$ model domain of the simulated (a) maximum hourly rainfall, (b) minimum temperature and (c) maximum $10 \mathrm{~m}$ wind speed from 00 UTC on 16 April to 00 UTC on 18 April 2019. Results are shown using the YSU (blue), UW (gray), MRF (purple) and MYNN (green) PBL schemes. Shown as well are results from the $0.25^{\circ}$ (red) and $0.1^{\circ}$ (orange) ERA5 products and rainfall estimates from GPM (black).

The circulation patterns in Figure 2 showed moisture transport over land from the Indian ocean on 17 April due to a ridging high pressure system. Figure 8a indicates that the various WRF simulations captured the difference in the moisture source between 16 and 17 April. The WRF configurations are associated with higher resolution than both ERA5 datasets and IMERG, and this capacity to simulate the moisture-terrain interactions may have been been a factor in producing the larger rainfall maxima over Zambia.

Figure $8 \mathrm{~b}$ shows simulated minimum temperatures, while Figure $8 \mathrm{c}$ shows maximum $10 \mathrm{~m}$ wind speeds. These results are indicative of the influence of convective rainfall on the formation and spreading of cold pools. The ERA5 minimum temperatures are higher than in the WRF simulations over most of the period, especially in the first and last twelve hours. The two ERA5 configurations are generally similar despite their different resolutions. The ERA5 maximum wind speed is consistently lower than in WRF, with very little difference between the $0.25^{\circ}$ and $0.1^{\circ}$ data. These points are consistent with an interpretation that the 
weaker maximum rainfall in the domain in ERA5 is associated with weaker surface cold pools. The same relationships have previously been found in idealized studies (e.g., [70]). Further support for the idea is that the YSU configuration simulated the largest maximum rainfall on 16 April, and this was matched by the lowest minimum temperature and the largest maximum wind speed of the WRF simulations. Likewise, the peak rainfall from the MRF configuration on 17 April is also associated with the lowest minimum temperature and slightly higher wind speeds.

The area maximum rainfall, minimum temperature and maximum wind over the $3 \mathrm{~km}$ domain were also studied for the 17 December 2016 and 21 January 2017 cases. The results are consistent with the main findings from the 17 April 2019 case, with the maximum rainfall from WRF far exceeding the IMERG and ERA5 maxima. YSU simulated the largest rainfall peaks for 17 December 2016. The ERA5 and ERA5_Land area minimum temperatures were higher than in all WRF simulations expect at 05h00 UTC, where ERA5_Land is lower. MYNN and MRF simulated the highest area maximum wind peak, followed by YSU whose peak occurred later. The ERA5 and ERA5_Land wind peaks are mostly similar, and much weaker than the values in the WRF simulations. For the 21 January 2017 case, YSU simulated the largest rainfall and strongest area maximum wind speed peak, followed by MYNN. The ERA5 and ERA5_Land comparison to WRF simulations is consistent across all three case studies, with ERA5 being associated with higher area minimum temperatures and the lower area maximum wind speeds.

The area hourly average rainfall, temperature and wind speed for the 17 April 2019 case are shown in Figure 9. The average rainfall from the IMERG satellite estimate and ERA5 reanalysis is greater than all the WRF simulations on 16 April. The situation is different on 17 April where WRF simulated more rainfall than IMERG and ERA5. ERA5 indicates a shorter-lived event within the $3 \mathrm{~km}$ domain, which peaks about four hours earlier than in IMERG. The different WRF configurations also produced a peak earlier than IMERG, with timing that is more similar to the ERA5 reanalysis; however, the simulated event is longer lived compared to ERA5. The start of the rainfall on 17 April is well matched between the YSU and UW simulations. Both these schemes take shallow convection into account. The simulations diverge beyond 1300 UTC, with YSU producing the most area averaged rainfall of all the schemes. The MYNN and MRF simulations also captured the event, although the peak was delayed by around an hour with MYNN compared to the other schemes.

The area hourly average rainfall is also shown for the two other case studies in Figure 10. The ERA5 and IMERG rainfall is higher than for all of the WRF simulations at the beginning of the simulation period, which should be considered as a spin up period. Champion and Hodges [71] found that model spin up for dynamical downscaling with the Unified Model is between 6 and $12 \mathrm{~h}$. Unlike the 17 April 2019 case, the IMERG area average rainfall estimate in the $3 \mathrm{~km}$ domain is generally higher than that in the WRF simulations for the 17 December 2016 and 21 January 2017 cases. The rainfall in these two cases is relatively long lived, persisting throughout the study period in both the satellite estimates and WRF simulations.

The general findings from the average temperature and wind results are similar across the three cases, and so these will be shown only for the 17 April 2019 case study (Figure $9 b, c)$. Relatively small differences are apparent in the WRF simulated average $2 \mathrm{~m}$ temperatures, with MYNN being slightly cooler than the others and YSU being slightly warmer during the peak on 17 April. The temperature peak occurs about two hours before the rainfall peak. The rainfall peak occurs at $14 \mathrm{~h} 00$ in the 17 December case with the average temperature peaking between $12 \mathrm{~h} 00$ and $13 \mathrm{~h} 00 \mathrm{UTC}$. The rainfall peak in the 21 January 2017 is observed at night, as shown in IMERG.

The ERA5 and ERA5_Land average wind speeds were markedly lower than in the WRF simulations during much of the period. The YSU scheme simulated slightly stronger winds, and the MYNN scheme slightly weaker winds amongst the WRF configurations. These points were consistent across all three case studies. 
a) Areal average hourly rainfall

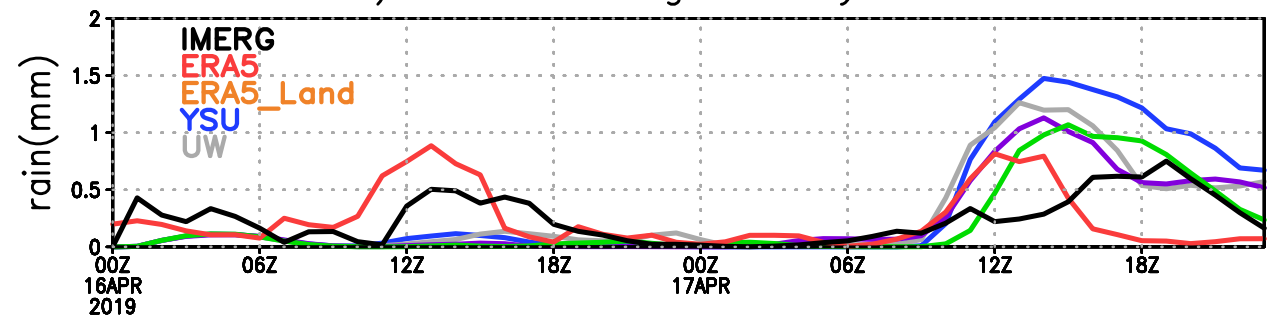

b) Areal average hourly temperature

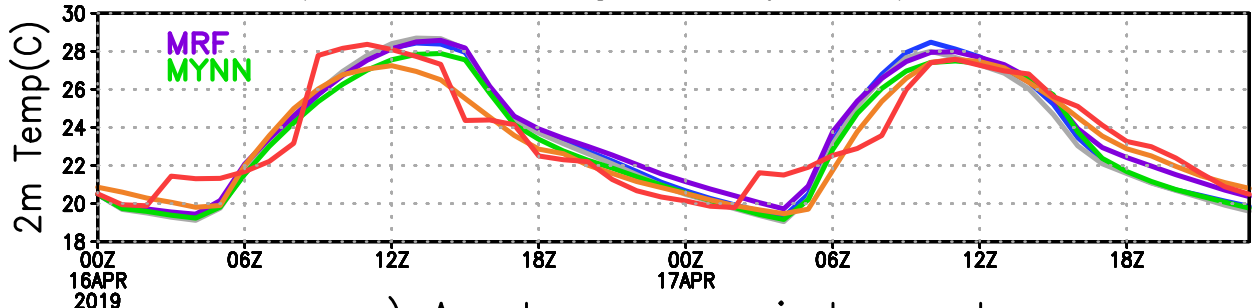

c) Areal average wind speed

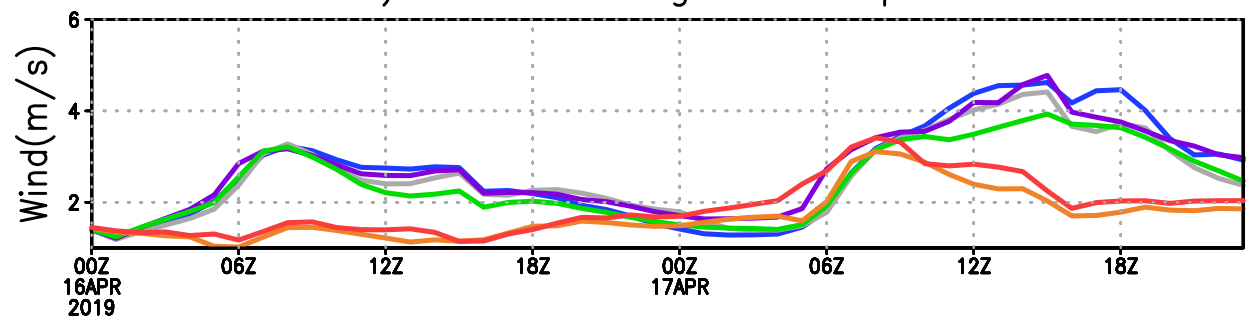

Figure 9. As in Figure 8 but for hourly averages rather than extreme values.

a) Areal ave hourly rainfall 17Dec2016

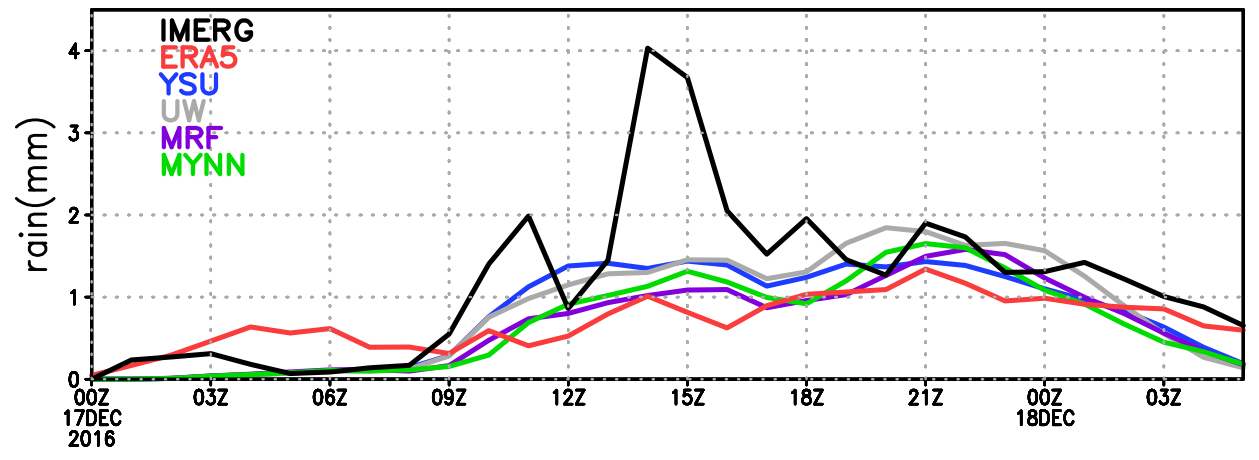

b) Areal ave hourly rainfall 21 Jan2017

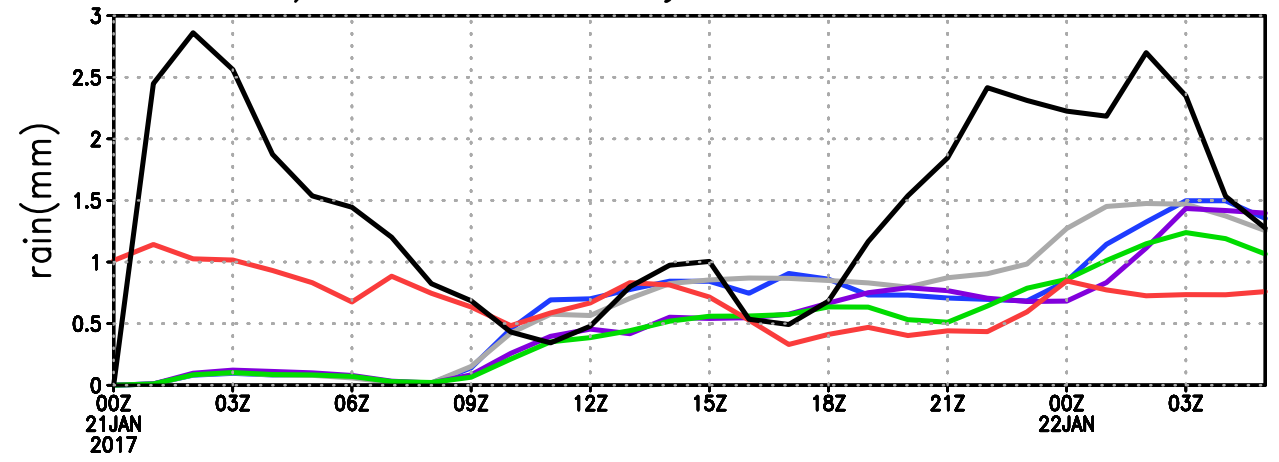

Figure 10. Area average hourly rainfall for the (a) 17 December 2016 and (b) 21 January 2017 case studies. 
In order to examine the spatial pattern of individual simulated thunderstorms, the WRF simulated rainfall between 1100 to 1200 UTC on 17 April 2019 is shown in Figure 11. The WRF model produced many separated rainfall objects, in contrast with the smoother, larger and weaker areas found in the lower resolution observational estimate and reanalysis product. The individual objects can produce large localized peaks, as confirmed by Figure 8, which showed that some objects are associated with rainfall close to or exceeding $100 \mathrm{~mm}$ within one hour, while the area average rainfall is less than $2 \mathrm{~mm}$ for all configurations (Figure 9). The convection occurs through the interplay of surface heating and topography, and local influences such as from previous convection, and the large-scale moisture transport from the Indian ocean caused by the ridging high pressure system. The location of the rainfall differs between ERA5 and IMERG, although both have the same grid length of $0.1^{\circ}$.

The WRF configurations using YSU and UW, which both consider shallow convection within the PBL scheme, simulated a line of thunderstorms at this time, which is aligned with topography north of Lake Kariba. These two simulations also generated numerous scattered objects with very light rainfall. The simulated structures using the MRF and MYNN schemes are broadly aligned north-west to south-east and east to west respectively. These configurations also produce broader areas with little or no rainfall.

a) IMERG Rain 11-12Z 17 Apr

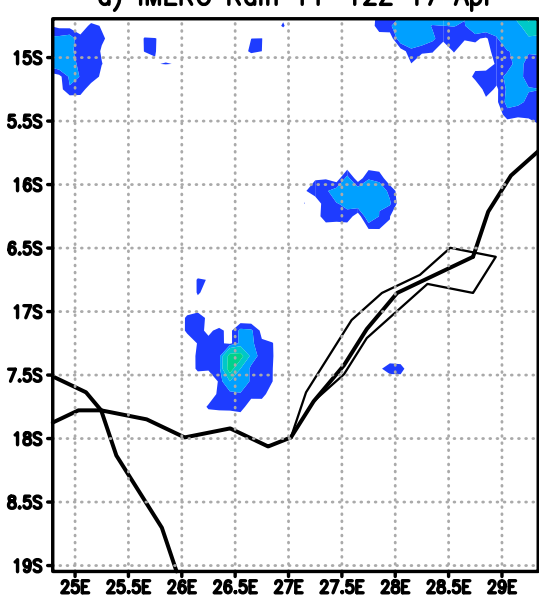

b) YSU Rain 11-12Z 17 Apr

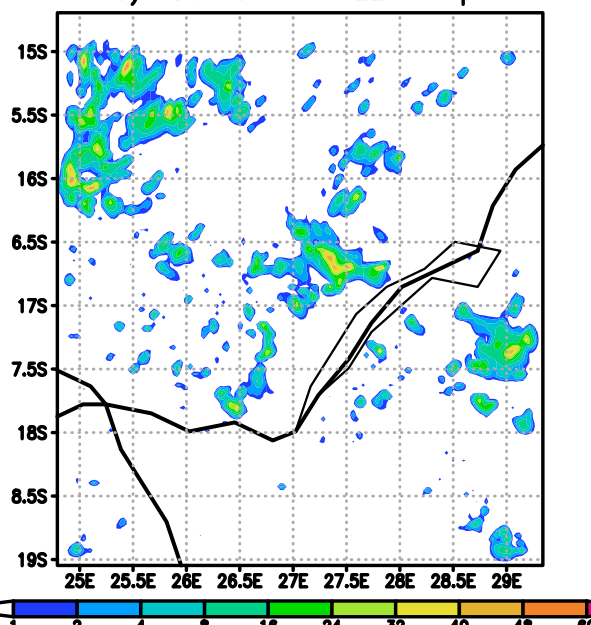

e) MRF Rain $11-12 Z 17 \mathrm{Apr}$

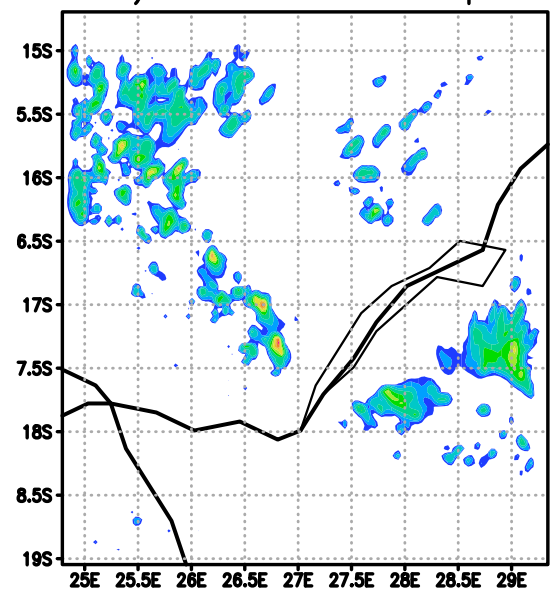

25E 25.5E 26E 26.5E 27E 27.5E 28́E 28.5E 29́E c) UW Rain 11-12Z $17 \mathrm{Apr}$

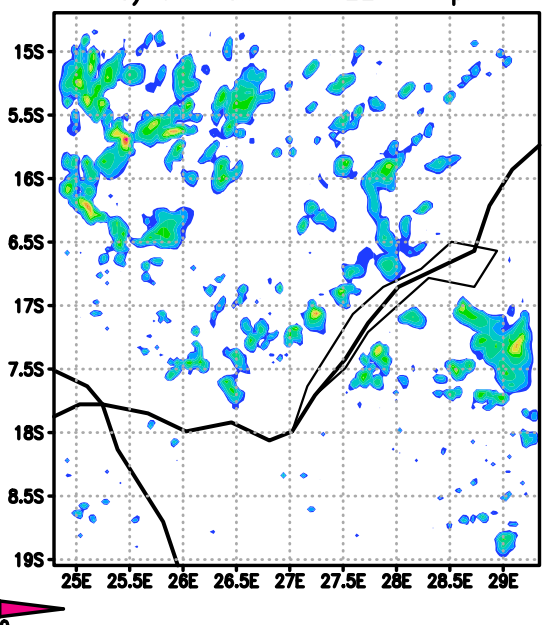

f) MYNN Rain 11-12Z $17 \mathrm{Apr}$

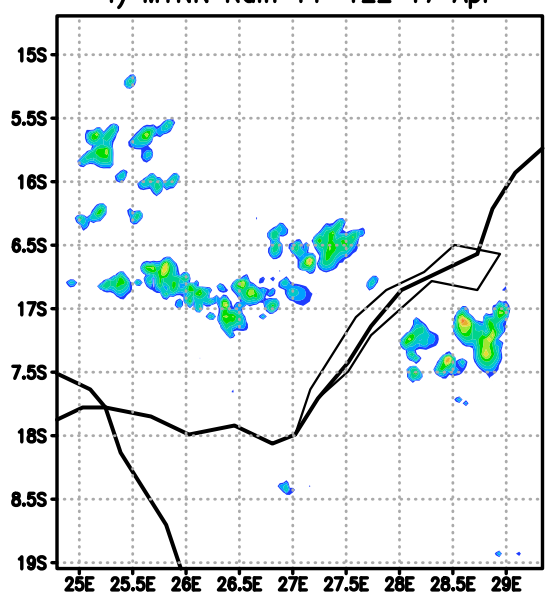

d) ERA5 Land Rain 11-12Z 17 Apr

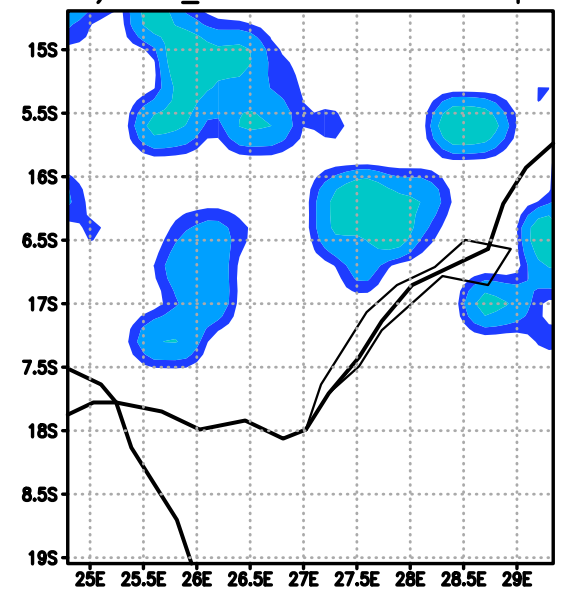

Figure 11. Rainfall (mm) simulated within the $3 \mathrm{~km}$ model domain between 1100 and 1200 UTC on 17 April 2019 in WRF runs using the (b) YSU, (c) UW, (e) MRF and (f) MYNN PBL schemes. The corresponding results from IMERG and from ERA5_Land are shown in $(\mathbf{a}, \mathbf{d})$ respectively. 


\subsection{The Planetary Boundary Layer Height}

The PBL height marks the transition from the boundary layer to the free atmosphere. It is associated with a diurnal cycle [72], and its value is influenced by the turbulence representation used. For example, in large-eddy simulations its value, and the boundary layer temperature profile, were found to differ between the Smagorinky and the dynamic Smagorinsky model, during both the morning transition [73] and CBL equilibrium stage [74]. The evolution of the PBL height as simulated by different configurations of WRF is shown for the 17 April 2019 case in Figure 12a. The diurnal cycle is clear, with a lower PBL height at night and early morning. The PBL height increases as the surface warms after sun-rise, reaching an average PBL height of greater than $1000 \mathrm{~m}$ with all WRF configurations. The most notable differences among the different schemes are that the area averaged PBL height is greatest using MRF and smallest using UW, while the decay in the early evening is delayed and is slower using the MYNN scheme.

The area minimum for each hour is shown in Figure 12b, and MYNN simulated a markedly higher minimum during all the simulated hours. It also has a higher PBL maximum (Figure 12c) between around 1500 to 0600 UTC, and a slower decay, which is consistent with the evolution of the area average. MRF usually had the highest area maximum at other times.

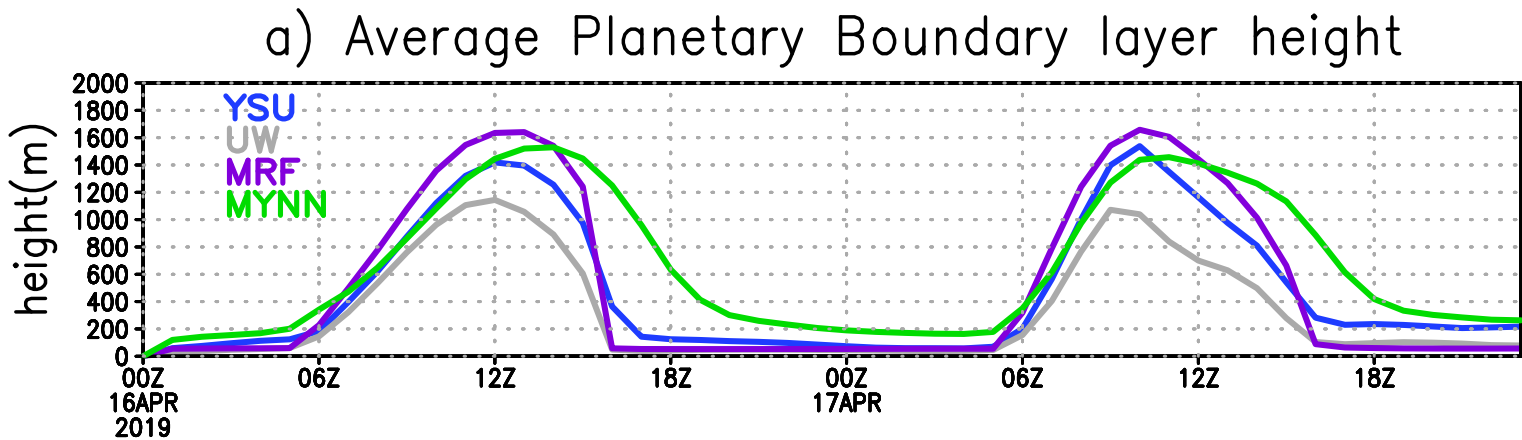

b) Minimum Planetary Boundary layer height

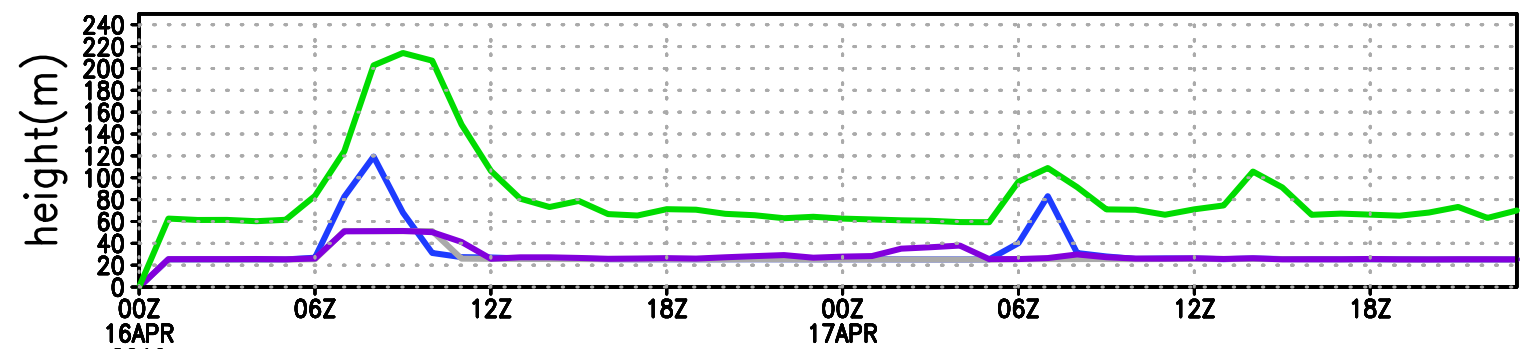

2019 c) Maximum Planetary Boundary layer height

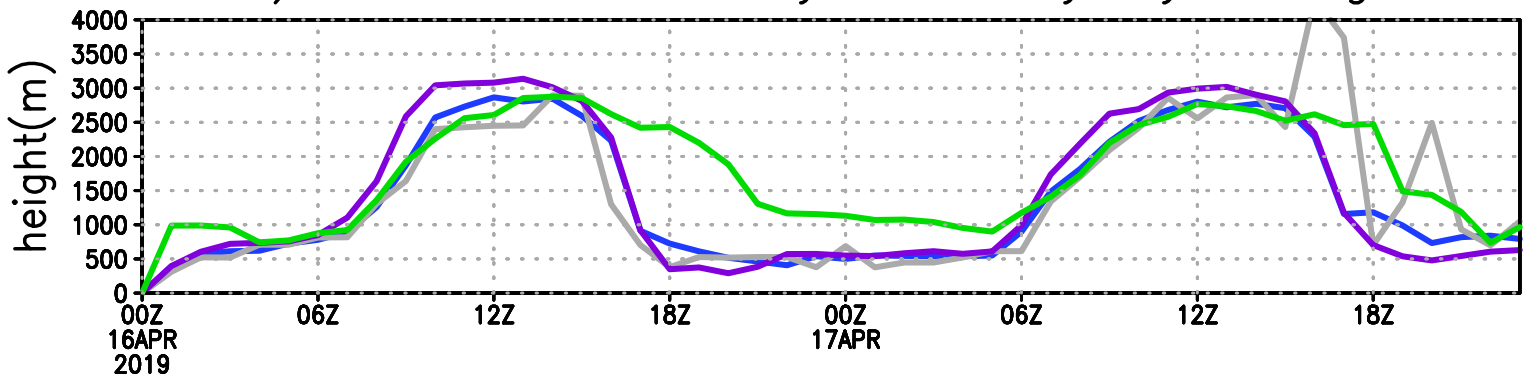

Figure 12. Timeseries for the $3 \mathrm{~km}$ model domain of the simulated (a) average, (b) minimum and (c) maximum PBL height from 00 UTC on 16 April to 00 UTC on 18 April 2019. Results are shown using the YSU (blue), UW (gray), MRF (purple) and MYNN (green) PBL schemes. 
The area average PBL height is shown for the two other case studies in Figure 13. The evolution of the PBL is similar across the three case studies, with MYNN being associated with a higher PBL height at night and MRF having a higher PBL height between 06h00 and 15h00 UTC. The peak in PBL height is almost the same for MYNN and YSU, with a more gradual decay for MYNN. UW consistently simulated the lowest daytime PBL height.

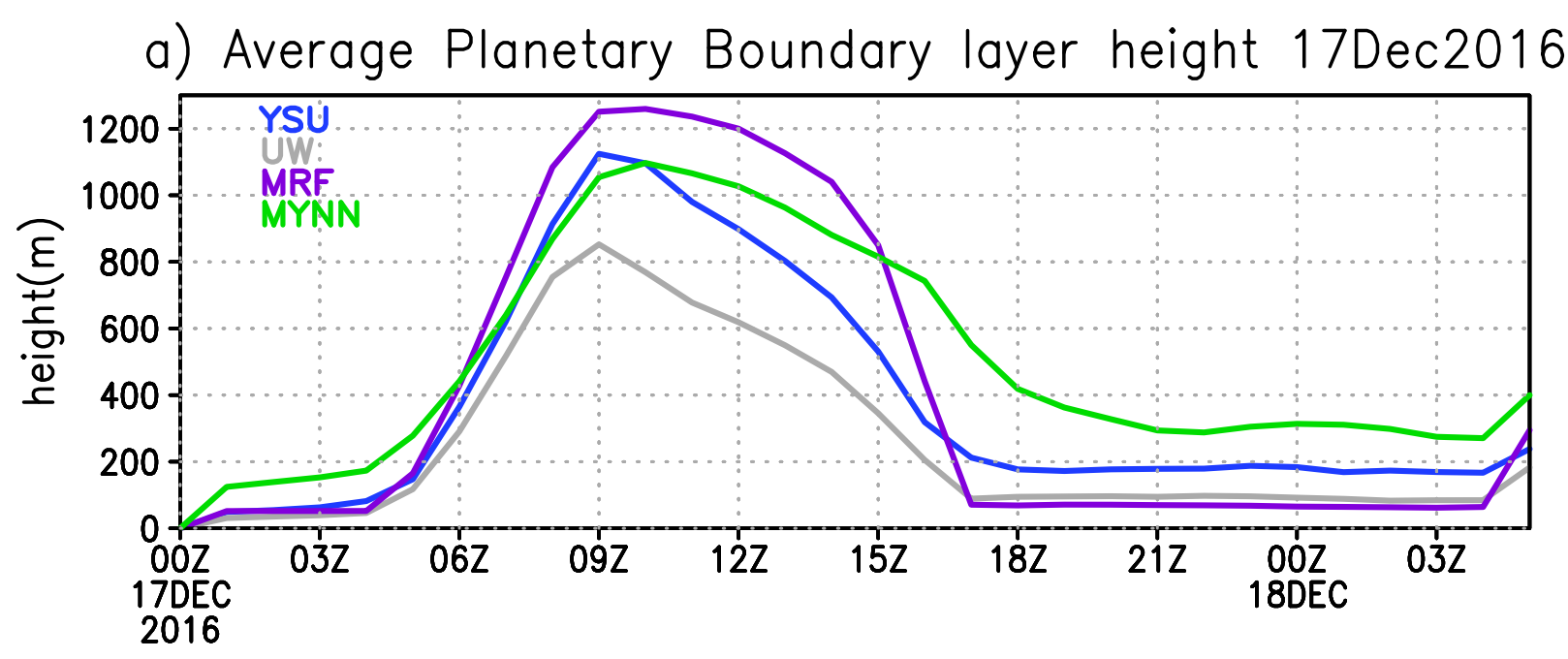

b) Average Planetary Boundary layer height 21Jan2017

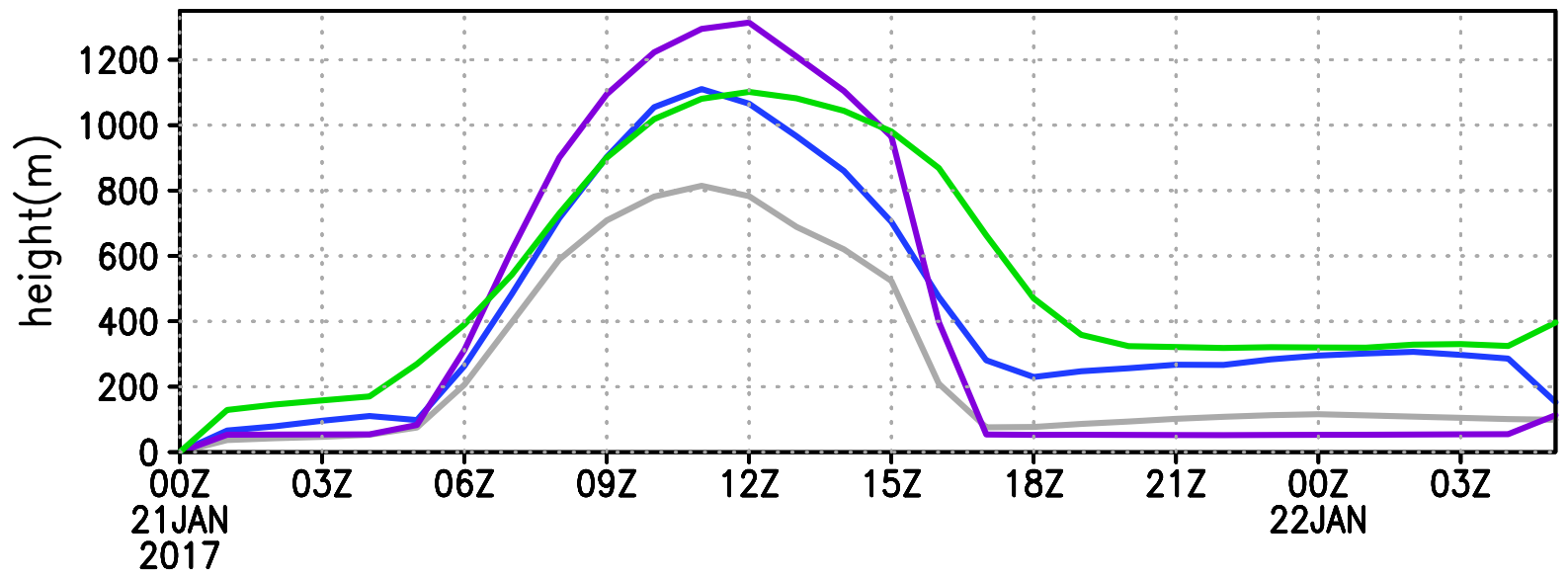

Figure 13. Timeseries for the $3 \mathrm{~km}$ model domain of the simulated average PBL height from (a) 00 UTC on 17 December to 06 UTC on 18 April 2016 and (b) 00 UTC on 21 January to 06 UTC on 22 Janaury 2017. Results are shown using the YSU (blue), UW (gray), MRF (purple) and MYNN (green) PBL schemes.

To gain some understanding of the spatial structure of the PBL heights, and how it relates to the rainfall distribution, we consider maps of the PBL height at 12h00 UTC on 17 April 2019 in Figure 14. These may be compared with the rainfall maps from Figure 11. It is immediately clear that the areas with low PBL heights occur predominantly at and around the areas of simulated rainfall. At this time Figure 12a showed that MYNN and MRF have the same BL height which is higher than with YSU and higher again than with UW. The low average height from UW is understandable from the spatial distribution (Figure 14b) as arising from the large area of PBL heights with values less than $600 \mathrm{~m}$. In contrast, MYNN is associated with a relatively small area of PBL heights less than $600 \mathrm{~m}$ (Figure 14d), matching the smaller area of rainfall in the preceeding hour (Figure 11f). The MRF simulation has a larger area of low PBL heights than MYNN (Figure 14c), but the same average is obtained because there are higher values in the south-west of the domain. 
The line of convective storms that is simulated by YSU (Figure 11b) in alignment with the topography can also be seen to have influenced the simulated PBL heights (Figure 14a).

a) YSU BLH $12 Z 17 \mathrm{Apr}$

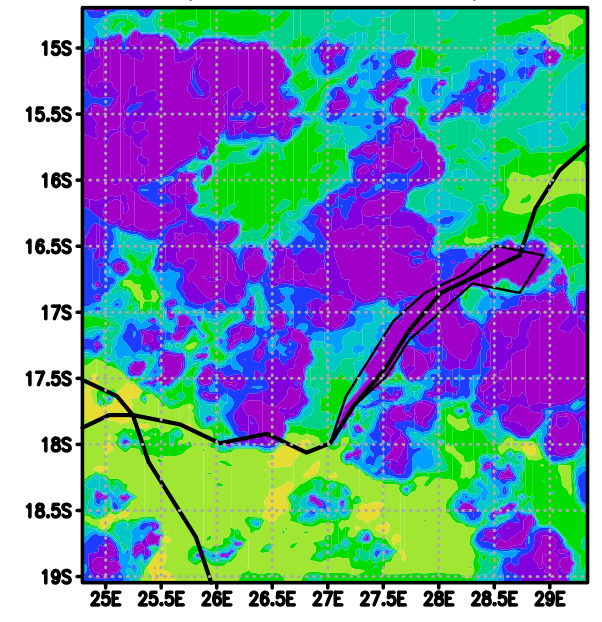

c) MRF BLH $12 Z 17 \mathrm{Apr}$

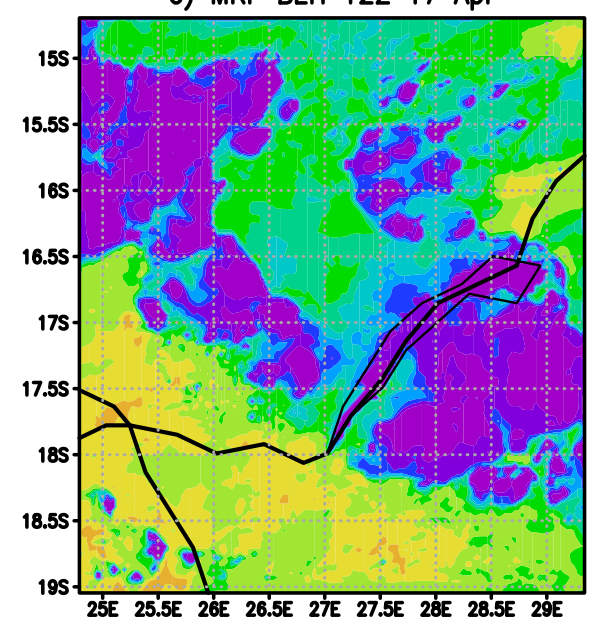

b) UW BLH $12 Z 17 \mathrm{Apr}$

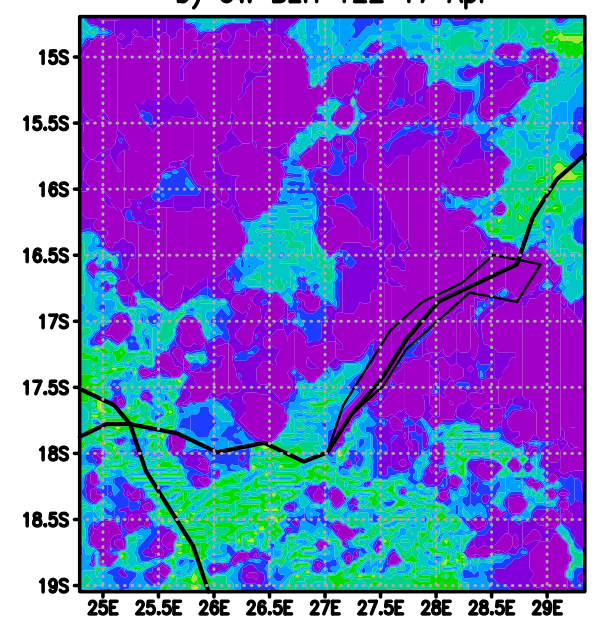

d) MYNN BLH $12217 \mathrm{Apr}$

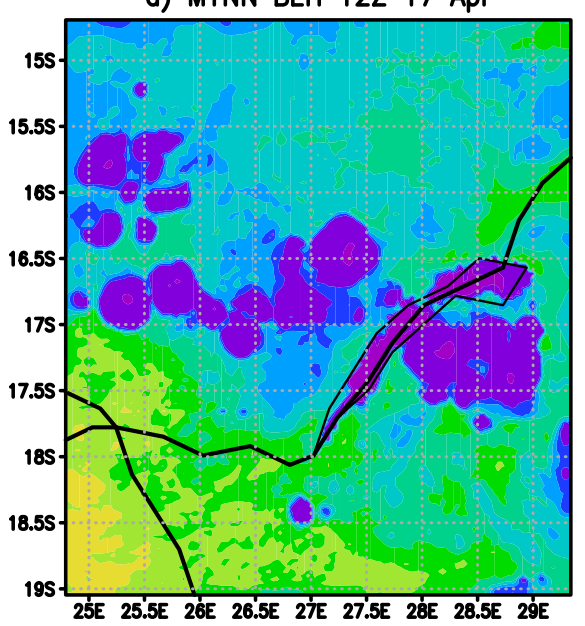

Figure 14. The PBL height at 12h00 UTC on 17 April 2019 in WRF simulations using the (a) YSU, (b) UW, (c) MRF and (d) MYNN PBL schemes.

All of the WRF configurations have some rainfall within the $3 \mathrm{~km}$ domain throughout 17 April 2019 (Figure 8) but the main period of intense simulated rainfall starts at around 10h00 UTC (Figure 9). In Figure 15 we show maps of the PBL height before that period, at 09h00 UTC. All of the WRF simulations produce low values of less than $600 \mathrm{~m}$ around Lake Kariba. The YSU (Figure 15a) and UW (Figure 15b) schemes have few locations with low PBL heights otherwise. The MRF scheme produced small values over a larger area that includes the lake (Figure 15c). This area is associated with the large peak in the maximum rainfall around the same time, as shown in Figure 8. However, MRF again simulated high values of PBL height over the south western part of the domain, leading it to have the largest area average PBL height at this time (Figure 12a). The lowest area average height occurred for the UW simulation, which has considerably larger areas with low PBL heights (Figure 15b). 
a) YSU BLH $09 Z 17 \mathrm{Apr}$

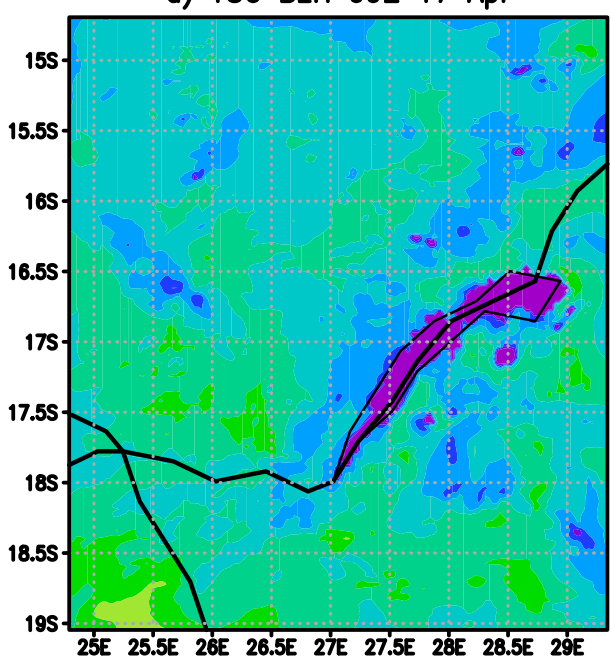

c) MRF BLH $09 Z 17 \mathrm{Apr}$

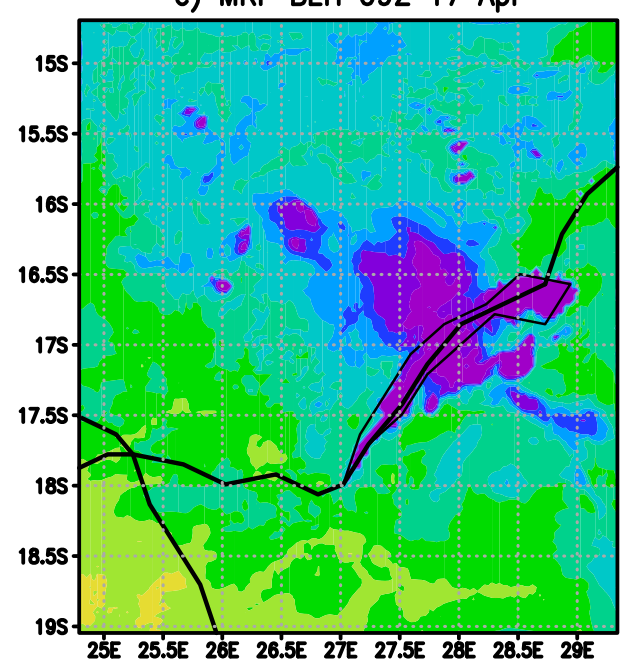

b) UW BLH $09 Z 17 \mathrm{Apr}$

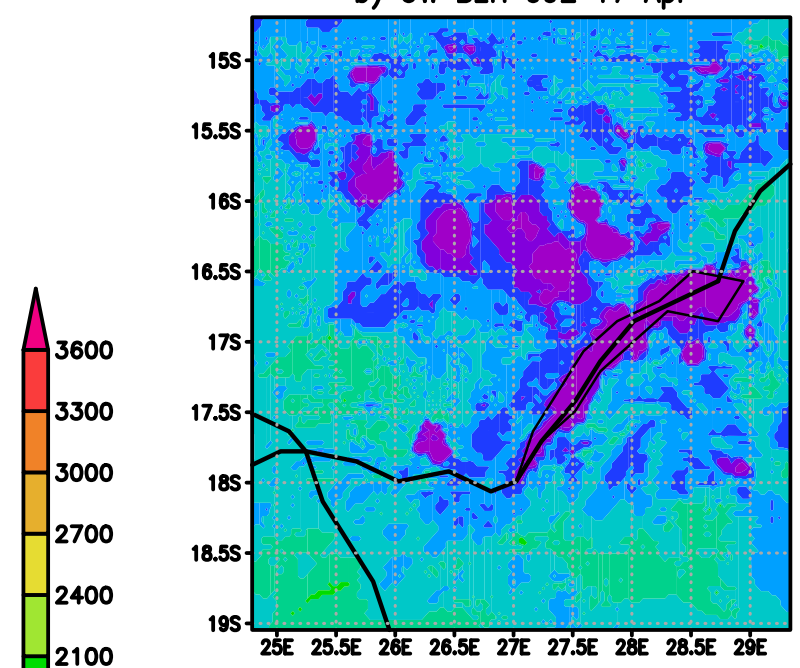

d) MYNN BLH $09 Z 17 \mathrm{Apr}$

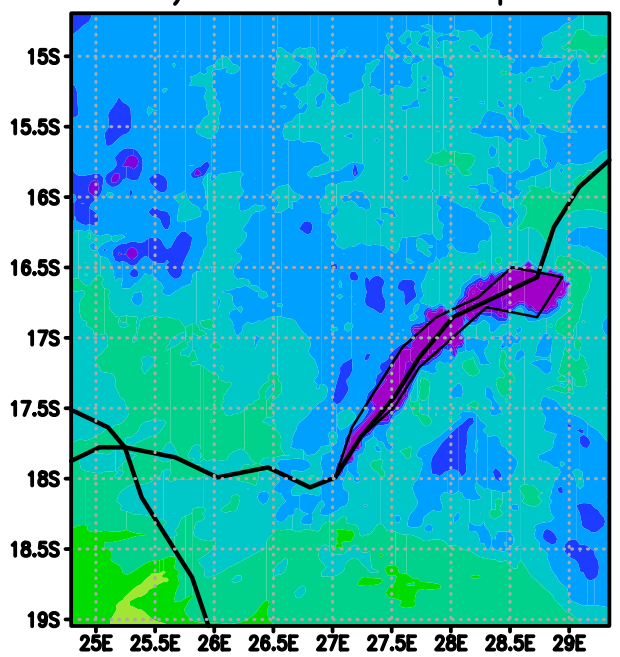

Figure 15. As in Figure 14 but for 09h00 UTC on 17 April 2019.

\subsection{Near-Surface Temperatures}

The analysis so far has demonstrated close connections between the spatial patterns of rainfall and associated low PBL heights. A plausible explanation for this connection would be the formation of cold pools by the convective storms, and their subsequent spreading as density currents over the surface. The layer of cold air at the surface would be expected to lead to a diagnosis of low PBL height. To test this idea, we have plotted spatial maps of $2 \mathrm{~m}$ temperature at 12h00 UTC in Figure 16 for comparison with the rainfall (Figure 11) and PBL heights (Figure 14). We also plot the temperature at 09h00 UTC in Figure 17. Indeed, there is a close correspondence between these spatial patterns for all of the schemes tested.

The temperatures simulated by UW at $12 \mathrm{~h} 00$ UTC (Figure 16a) are lower compared to other configurations over most of the northern part of the domain. This result is consistent with the lower PBL heights which were found in this configuration (Figure 14a), and with the convection elements distributed over much of this area (Figure 11a). The MYNN simulation is also found to be generally cooler, compared to MRF and YSU in this same area (Figure 16d). Over the south western parts of the domain, MYNN is also somewhat cooler than the other configurations. The north-west to south-east aligned rainfall (Figure 11d) and PBL height pattern (Figure 14d) is associated with cooler temperatures in the MYNN simulation. MYNN does not simulate temperatures higher than $34{ }^{\circ} \mathrm{C}$, which were produced by all other configurations along the eastern border of the $3 \mathrm{~km}$ 
domain. Interestingly MRF does not appear to be much warmer in the south western part of the domain (Figure 16c) where high PBL heights were diagnosed by this PBL scheme (Figure 14c).

a) YSU Temp $12 Z 17 \mathrm{Apr}$

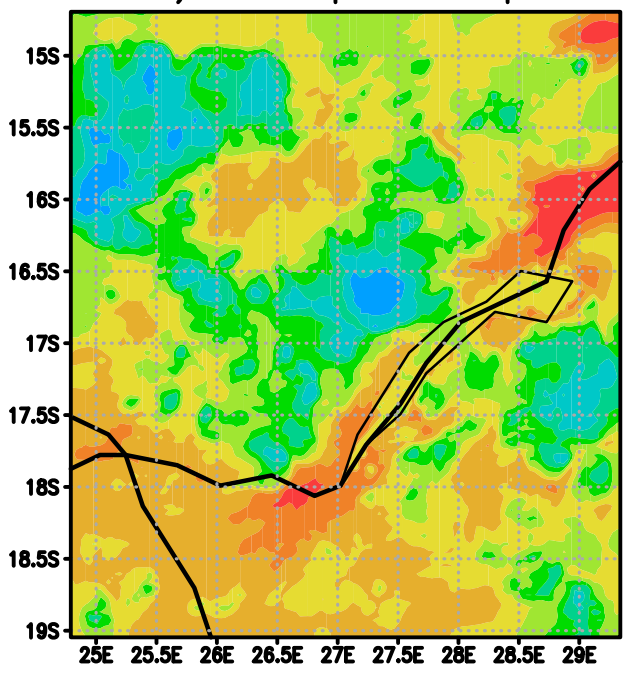

c) MRF Temp $12 Z 17$ Apr

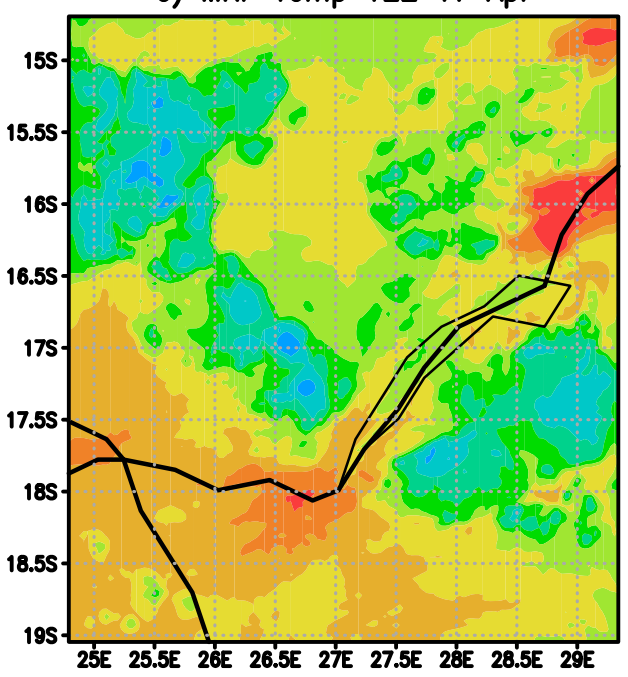

b) UW Temp $12 Z 17 \mathrm{Apr}$

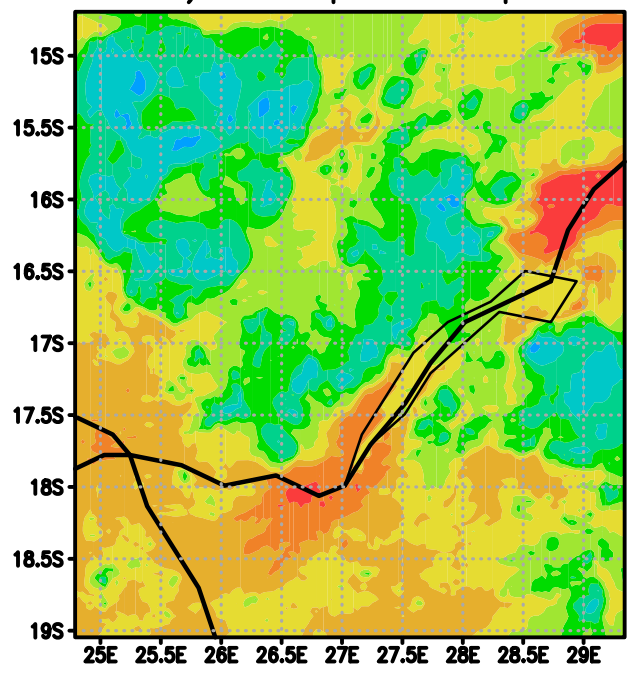

d) MYNN Temp $12 Z 17$ Apr

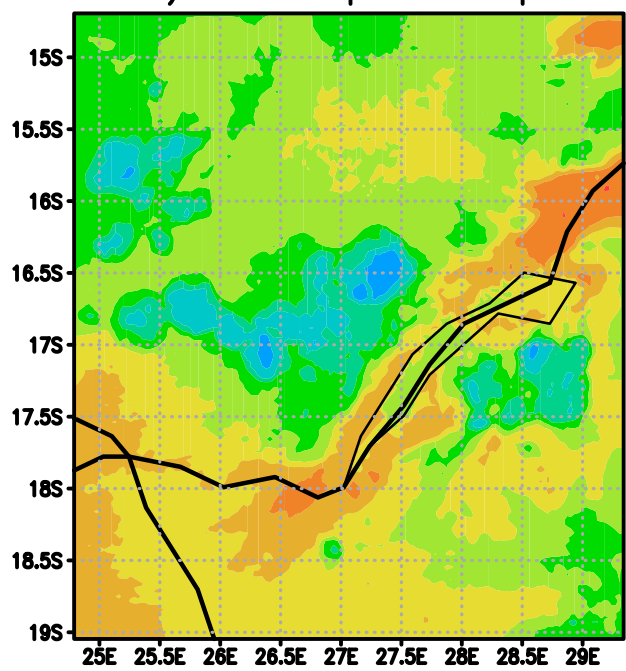

Figure 16. The temperature at 12h00 UTC on 17 April 2019 in WRF simulations using the (a) YSU, (b) UW, (c) MRF and (d) MYNN PBL schemes.

At 09h00 UTC, UW was found to be associated with lower PBL heights (Figure 12b) but its simulated temperatures are not generally lower compared to other schemes (Figure 15b). Rather, the MYNN scheme simulated lower temperatures in general (Figure 15b). Thus, there is a less direct relationship between PBL heights and surface temperatures at this time, in the absence of significant rainfall and cold pool formation. We note also that YSU simulated higher temperatures in general compared to MRF (Figure 16a,c), even though MRF produced higher BL heights (Figure 14a,c). However, the region that was associated with lower PBL heights in the MRF simulation at $09 \mathrm{~h} 00 \mathrm{UTC}$, which was related to rainfall above, was found to be associated with lower temperatures. 
a) YSU Temp $09 Z 17 \mathrm{Apr}$

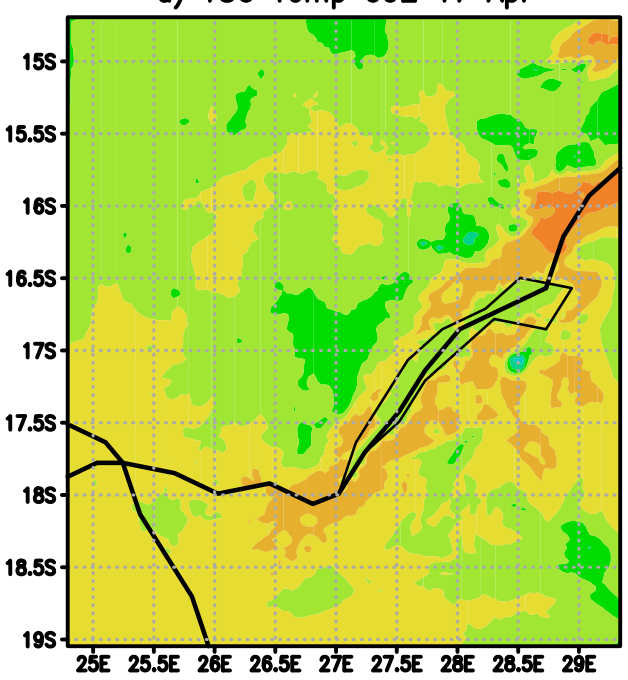

c) MRF Temp $09 \mathrm{Z} 17 \mathrm{Apr}$

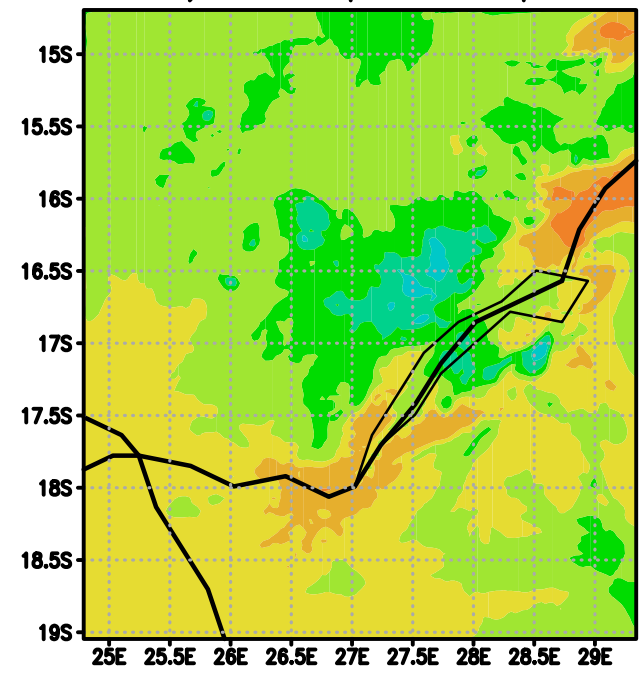

b) UW Temp 09Z $17 \mathrm{Apr}$

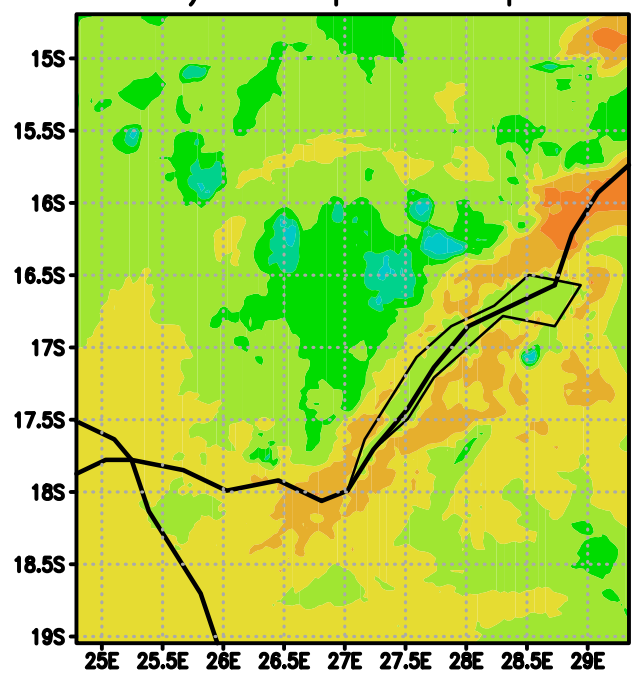

d) MYNN Temp $09 Z 17$ Apr

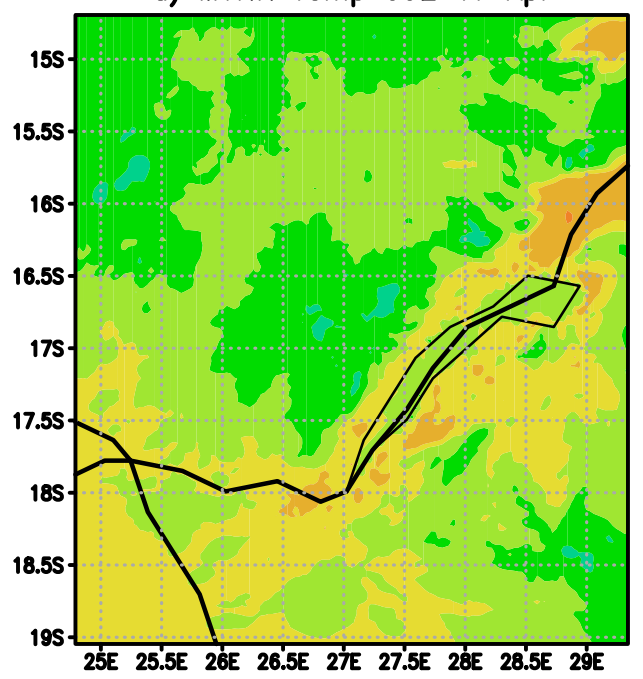

Figure 17. As in Figure 14 but for 09h00 UTC on 17 April 2019.

\subsection{Verification Statistics}

In this section, the performance statistics are discussed for simulated rainfall using the four PBL schemes compared with IMERG. IMERG produced larger rainfall amounts compared to the ERA5_Land and TAMSAT products, which underestimated rainfall compared to the available ground station data for two of the three cases. The statistics are summarized in Figure 18 and were calculated with the MODE tool in MET, as described in Section 3.4.

The PODY is generally higher for YSU and UW, and MYNN produced the lowest scores for the 17 December 2016 and 17 April 2019 case studies. The CSI and PODY statistics show similar relative performances of the different PBL schemes. However, the FAR is also higher for YSU and UW, with MYNN being associated with the lowest FAR in general. The models' performances on 17 December 2016 and 21 January 2017 are generally similar; worse performances occurred for the 17 April case (note the change of scale in Figure 18c). Differences in scores between the different PBL schemes are more readily apparent for the 17 April 2019 case. 
17 December 2016

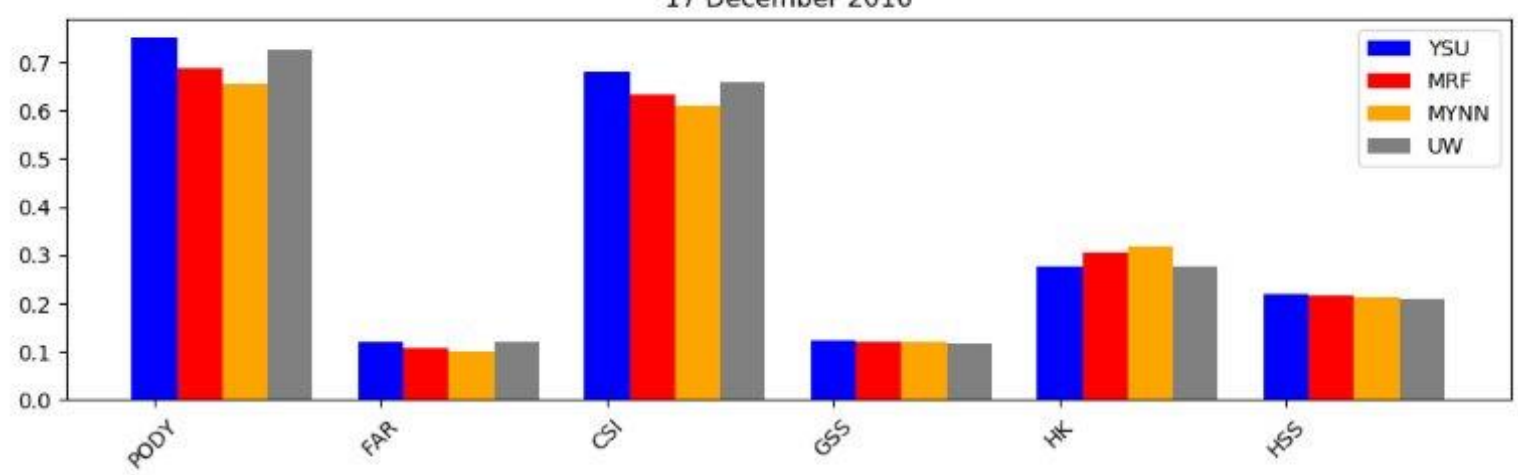

21 January 2017

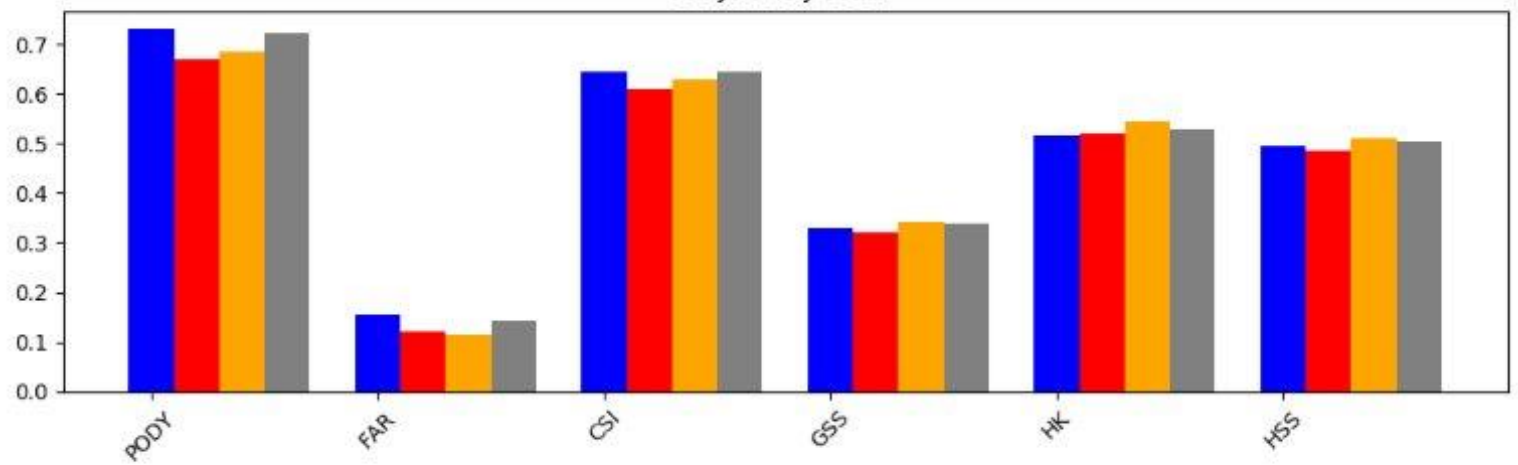

17 April 2019

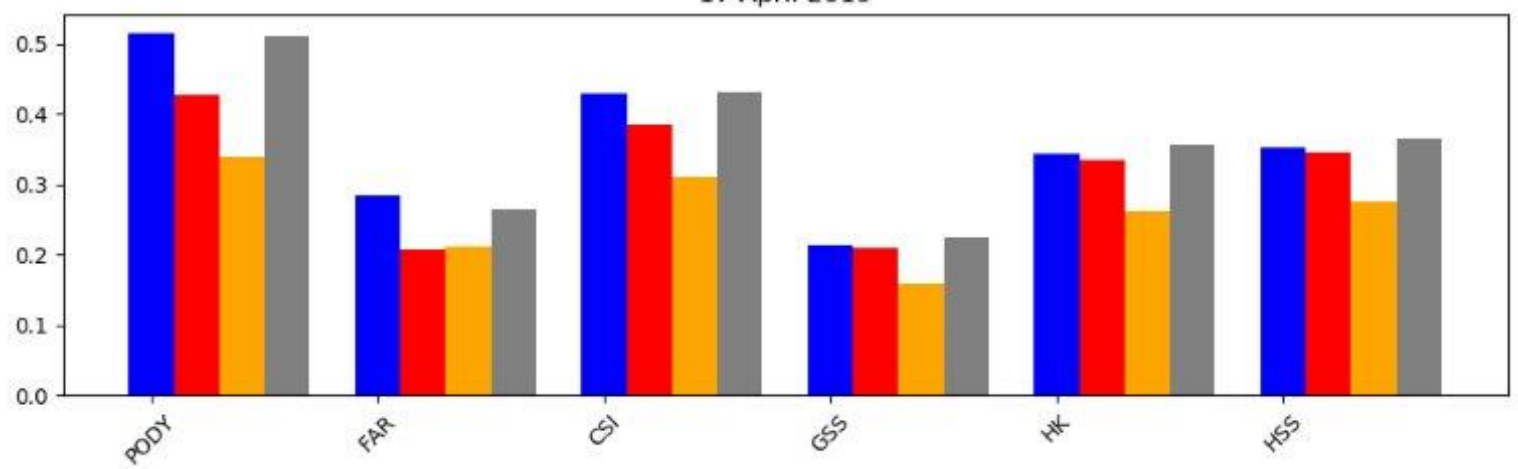

Figure 18. Contingency table statistics calculated using MODE Tools for (a) 17 December 2016, (b) 21 January 2017 and (c) 17 April 2019. The various quantities calculated are described in Section 3.4. Results are shown using the YSU (blue), UW (gray), MRF (red) and MYNN (yellow) PBL schemes.

The GSS is lower than the CSI, and the YSU and UW schemes do not stand out relative to the others for this metric, in contrast to PODY and CSI. A similar remark holds for the HSS, where the MRF and MYNN are found to be slightly better in some instances, compared to YSU or UW. This suggests that the higher PODY, CSI and FAR scores of UW and YSU occur partly through random chance, because they tend to produce more rainfall "events" (as in Figure 11 for example). Nonetheless, the MYNN GSS and HSS are clearly lower than those of other schemes for the 17 April 2019 case study. The HK scores also show some similar results across schemes, with YSU and UW performing at the same level or slightly worse than MRF and MYNN on 17 December 2016 and 21 January 2017. For the 17 April 2019 case study, MYNN again stands out with a lower HK score.

ZMD minimum and maximum temperature observations were also used to test the performance of different PBL schemes. The number of stations used differed per case, ranging from 13 to 18 distributed across Zambia. The observed maximum temperatures for all three cases are shown in Figure 19 to show the distribution of the available stations. Not all stations are available for all the events-the April 2019 event being associated with 
fewer stations. The corresponding simulated maximum temperature obtained from threehourly data for the YSU PBL scheme are also shown for eye ball verification. The results suggest that the model generally underestimated the maximum temperature. The model data were interpolated to the available stations for each case with a bilinear interpolation method, using the nearest four grid points. The interpolated data were then used with the corresponding observations to generate the ME and RMSE shown in Table 3 for all PBL schemes, and the three case studies.

a) Stats Max Temp 17 Dec 2016

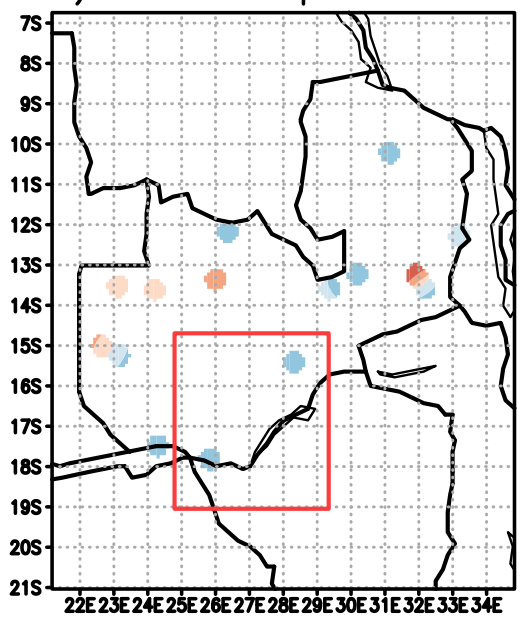

d) YSU Max Temp 17 Dec 2016

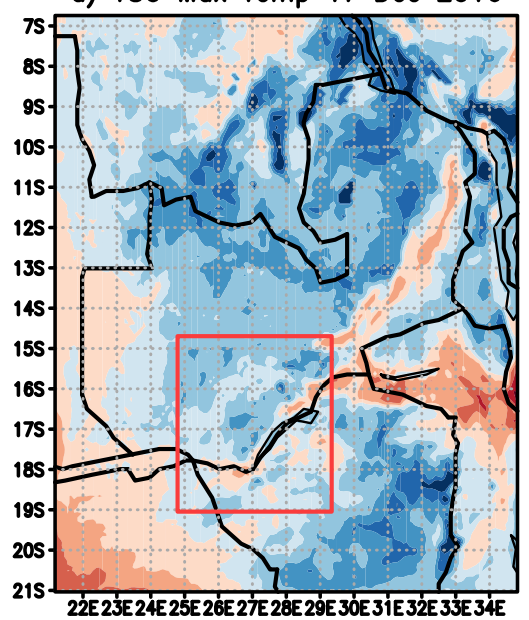

b) Stats Max Temp 21 Jan 2017

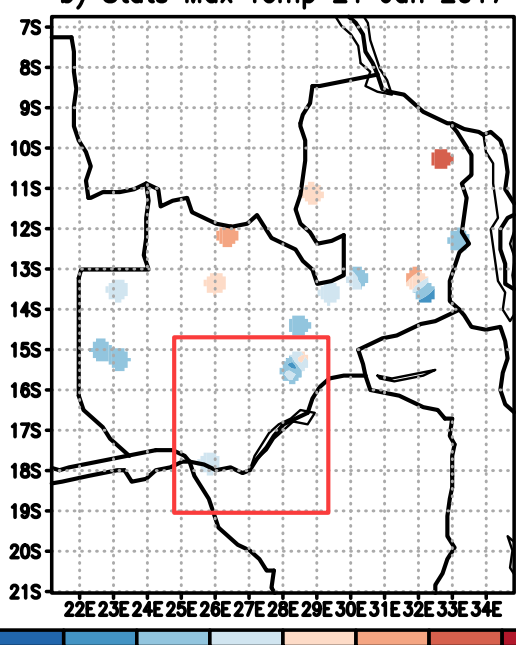

e) YSU Max Temp 21 Jan 2017

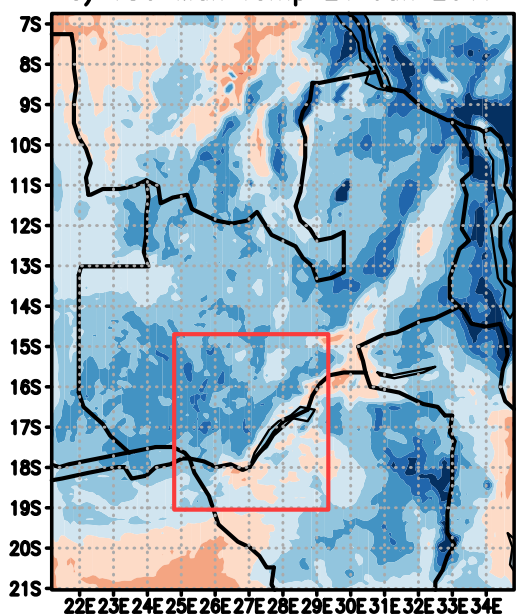

c) Stats Max Temp 17 Apr 2019

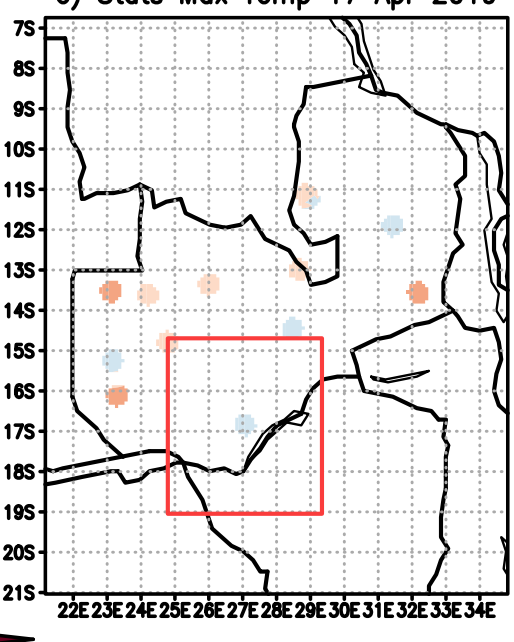

f) YSU Max Temp 17 Apr 2019

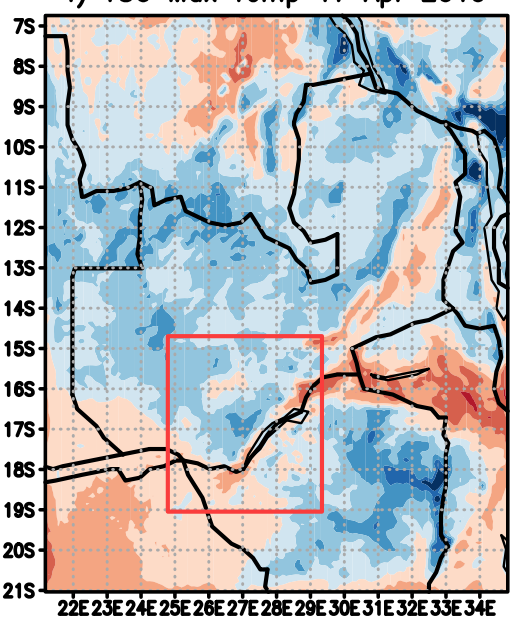

Figure 19. Observed station maximum temperatures on (a) 17 December 2016, (b) 21 January 2017 and (c) 17 April 2019 , and WRF simulated maximum temperature using YSU on (d) 17 December 2016, (e) 21 January 2017 and (f) 17 April 2019 based on three hourly output.

WRF underestimated the maximum temperature for all the case studies (Table 3). MYNN is associated with the largest bias of all the PBL schemes, while the ranking for the other schemes differs per case study. YSU has the lowest bias for the 17 December 2016 case, MRF for 21 January 2017, and UW for 17 April 2019. The same result was found for the RMSE, with MYNN being associated with the largest RMSE. For minimum temperature, WRF simulated a slight warm bias for the 17 December 2016 case and 17 April 2019 case studies, and a cool bias for MRF and MYNN for 21 Janaury 2017. MRF is associated with the lowest RMSE for all the cases, when compared to YSU and UW, while MYNN has the lowest of all for the 17 December 2016 case study. 
Table 3. The mean error and root mean square error for the three case studies with four PBL schemes.

\begin{tabular}{cccccc}
\hline \multicolumn{5}{c}{ 17 December 2016 } \\
\hline \multirow{2}{*}{ Tmax } & Bias & -1.32012749 & -1.38775444 & -2.77817154 & -1.38088036 \\
& RMSE & 0.486743391 & 0.493839473 & 0.977323115 & 0.588211000 \\
\hline \multirow{2}{*}{ Tmin } & Bias & 1.46163368 & 1.44644737 & 1.04733276 & 1.35207367 \\
& RMSE & 0.352237523 & 0.259509355 & 0.141910866 & 0.322271198 \\
\hline \multicolumn{5}{c}{ 21 January 2017 } \\
\hline \multirow{5}{*}{ Tmax } & Bias & -2.41129112 & -2.37238693 & -3.80073738 & -2.59328842 \\
& RMSE & 1.05125797 & 0.493839473 & 1.18280017 & 1.01926601 \\
\hline \multirow{2}{*}{ Tmin } & Bias & 0.257066727 & -0.03591537 & -0.09047127 & 0.197696686 \\
& RMSE & 0.765877962 & 0.259509355 & 0.620617151 & 0.802365541 \\
\hline \multirow{5}{*}{ YSU } & $\mathbf{1 7}$ April 2019 & UN \\
\hline \multirow{2}{*}{ Tmax } & Bias & -2.97936249 & -2.92316628 & -4.44790268 & -2.87375450 \\
& RMSE & 1.00955522 & 1.01955235 & 1.48482561 & 0.488890052 \\
\hline \multirow{2}{*}{ Tmin } & Bias & 0.302921295 & 0.432020187 & 0.01034927 & 0.177062988 \\
& RMSE & 0.603425622 & 0.444622010 & 0.662797749 & 0.645322680 \\
\hline
\end{tabular}

\section{Summary and Conclusions}

Sensitivity tests of three heavy rainfall events that took place over Zambia with different PBL schemes were conducted using the WRF model. The events were associated with over $90 \mathrm{~mm}$ of rainfall in a 24 hour period for at least one ground station in the southern part of Zambia. During all three events there was a ridging Atlantic Ocean high, resulting in an onshore flow that transported moist air from the Indian ocean onto the subcontinent. The GFS captured the synoptic conditions, with higher pressure associated with the 17 April 2019 event. The pressure over land, however, was generally found to be lower than in the ERA5 reanalysis. Uplift occurred due to surface heating and terrain, resulting in isolated convection cells over the area of interest. The role of surface heating is indicated by the lag of about 2 to $4 \mathrm{~h}$ between the peak in temperatures and the peak in area average rainfall. Kanno et al. [18] also found a strong diurnal cycle in the rainfall of Zambia, indicating strong afternoon convection, and large spatial differences in sites that they studied due to differences in topography.

IMERG and TAMSAT satellite rainfall estimates, and ERA5 and ERA5_Land reanalysis data, were used to study the spatial distribution of the rainfall during the three events. IMERG produced rainfall amounts larger than $75 \mathrm{~mm}$ in parts of Zambia for all three events, while TAMSAT rainfall was less than $40 \mathrm{~mm}$ for two of the events, with higher amounts for the 17 April 2019 event. The ERA5 and ERA5_Land rainfall totals were also mostly less than $40 \mathrm{~mm}$ over Zambia. It may be noted that the ERA5_Land has a similar spatial resolution to IMERG. Given that the three events were selected because at least one ground observation reported over $90 \mathrm{~mm}$ of rainfall, we conclude that IMERG provides the best estimate of extreme rainfall. The QPE from TAMSAT for the 17 December 2016 and 21 January 2017 case studies is consistent with other recent studies in the region, in the sense that values were severely underestimated in simulating heavy rainfall associated with an ex-tropical cyclone [64] and a cut-off low system [66]. It may be noted that the ZMD station rainfall was used to calibrate the TAMSAT QPE [10,55]. The location of maximum rainfall differed across the different observational estimates, with none of them capturing the largest values of rainfall found in the station observations. 
Two of the PBL schemes used include a non-local term, while the other two are based on TKE. One of the non-local PBL schemes, and one of the TKE scheme also represent mixing due to shallow convection. The simulations were made with a grid length of $9 \mathrm{~km}$ in the outer domain that covers all of Zambia and a child domain with $3 \mathrm{~km}$ grid spacing which covers all of the available ground observations on 17 April 2019. It also includes Lake Kariba and the border between Zimbabwe and Zambia. A convection parametrization was left on when a grid spacing of $9 \mathrm{~km}$ was employed and switched off for the child domain. All of the model configurations underestimated rainfall in the outer domain for all three case studies. Somses et al. [66], who used the same convection scheme as in the current study, and Champion and Hodges [71] found similar results, that switching on the convection scheme results in lower rainfall intensities. Steeneveld and Peerlings [75] compared simulations of a hail storm over the Netherlands using different convection schemes, and concluded that scale-aware convection schemes can be beneficial for the representation of deep convection in the gray zone.

Some small intense storms were simulated within the $3 \mathrm{~km}$ model domain for all three case studies, and with all four PBL schemes. The MYNN scheme simulated a smaller area of rainfall compared to other schemes during the 21 January 2017 and 17 April 2019 case studies. YSU produced the highest hourly rainfall peaks for all three events. The MODE statistics show similar performance of YSU and UW for all three case studies. These two schemes produce the highest PODY and CSI scores for all the events, but the higher skill scores are not maintained when random hits are accounted for. For the 17 April 2019 case, MYNN was the worst performing scheme according to all of the scores other than FAR. The evolution of the PBL height is similar across all the three events, with MRF being associated with the highest values, and UW the lowest values during the peak times. The decay of the convective PBL is slower in MYNN, which has a higher PBL average at night and during the early mornings. The spatial distribution of rainfall was found to be associated with lower temperatures, higher wind speeds and a lower BL height, consistent with the interpretation that there was an important role for cold pools in producing different evolutions of the simulations for the different PBL schemes. However, even in the absence of rainfall, UW simulated smaller values of the PBL height. Regarding temperature, MYNN was found to be generally cooler compared to other schemes.

A number of previous studies have compared different PBL schemes to identify the best performing amongst local, non-local and hybrid local-non-local schemes. Hu et al. [30] found YSU to outperform one local PBL scheme, and was generally as good as a hybrid scheme in the United States. Cohen et al. [28] concluded that a hybrid scheme performed better than the two nonlocal schemes tested here, the MRF and YSU, due to overmixing of the PBL. Cintineo et al. [76] found that cloud fields were less sensitive to PBL schemes compared to cloud microphysics schemes. A study over the Highveld of South Africa found local schemes to perform better in general during winter, although YSU performed better in the same period for simulating relative humidity [31]. The study compared two local schemes, one hybrid scheme and one non-local scheme, and concluded that no single scheme can be selected as best performing across all sites analysed in the Highveld. We draw a similar conclusion here for extreme rainfall over Zambia. The choice of PBL scheme does have clear effects on the morphology of the rainfall patterns, and on the near-surface temperatures and wind speeds, but no scheme provides consistent and markedly better skill across the three cases. However we observe that UW is associated with a consistently lower PBL height implying weaker mixing, and that there is relatively strong mixing with the MRF scheme. MYNN stood out as the worst performer for the 17 April 2019 case, even when accounting for random hits. MYNN also resulted in the largest cool bias when simulating maximum temperature across all cases. We therefore support the use of YSU as recommended for the tropical suite by Wang [42].

The lack of intense rainfall when the Tiedtke convection scheme is switched on suggests a need to test the suitability of alternative convection schemes when a grid length of less than $10 \mathrm{~km}$ is used in the region. Our study also points to a clear need for more 
ground observations that would greatly assist studies on the performances of different model configurations, not least because the reanalysis and satellite estimates gave some contrasting results. Kanno et al. [18] also concluded that the existing meteorological stations were too sparse to use for local meteorological studies. In their situational analysis Venäläinen et al. [4] recommended an increase in the number of ground observations and procurement of a radar system and a lightning detection system for ZMD. A weather radar system would allow model simulations to be evaluated in three dimensions with finer space and time resolutions. A limitation of our study is that it focused only on heavy rainfall events associated with a ridging high pressure system. Further future studies are necessary for different types of weather events.

Author Contributions: M.-J.M.B., R.S.P., D.W., E.N. and S.M. conceptualized the study; D.W., H.S., M.-J.M.B. and R.M. implemented the WRF model (software); M.-J.M.B., D.W., R.S.P. and E.P. did formal analysis; H.S., S.M. and E.R. provided computational resources; M.-J.M.B. and E.R. acquired funding; M.-J.M.B. wrote the original draft; D.W., R.S.P., H.S. and R.M. reviewed and edited the text. All authors have read and agreed to the published version of the manuscript.

Funding: This research was partially funded through the Climate Research for Development (CR4D) fellowship grant number CR4D-19-11 managed by the African Academy of Sciences. The work is also supported by the South African Department of Science and Innovation to implement the SADC Cyber-Infrastructure Framework.

Institutional Review Board Statement: Not applicable.

Informed Consent Statement: Not applicable.

Data Availability Statement: The TAMSAT satellite precipitation estimates can be obtained from https:/ / www.tamsat.org.uk, while IMERG is available from https:/ / storm.pps.eosdis.nasa.gov/ storm. The ERA5 reanalysis can be obtained from https://cds.climate.copernicus.eu. The station observations are available on request from the Zambia Meteorological Department.

Acknowledgments: The authors acknowledge ZAMREN and the South African Centre for High Performance Computing (CHPC) for use of their HPC system. ZMD is also acknowledged for provision of ground observations.

Conflicts of Interest: The authors declare no conflict of interest. The funders had no role in the design of the study; in the collection, analyses or interpretation of data; in the writing of the manuscript, or in the decision to publish the results.

\section{References}

1. Centre for Research on the Epidemiology of Disasters. The Human Cost of Weather Related Disasters 1995-2015; The United Nations Office for Disaster Risk Reduction, United Nations: Geneva, Switzerland, 2015; pp. 1-27.

2. World Meteorological Organization (WMO). State of the Climate in Africa 2019; WMO: Geneva, Switzerland, 2020; Volume 1253, pp. 1-35.

3. United States Agency International Development (USAID). Climate Change Adaptation in Zambia; USAID: Washington, DC, USA, 2020; pp. 1-4.

4. Venäläinen, A.; Pilli-Sihvola, K.; Tuomenvirta, H.; Ruuhela, R.; Kululanga, E.; Mtilatila, L.; Kanyanga, J.K.; Nkomoki, J. Analysis of the meteorological capacity for early warnings in Malawi and Zambia. Clim. Dev. 2015, 8, 1-7. [CrossRef]

5. Skamarock, W.C.; Klemp, J.B.; Dudhia, J.; Gill, D.O.; Liu, Z.; Berner, J.; Wang, W.; Powers, J.G.; Duda, M.G.; Barker, D.M.; et al. A Description of the Advanced Research WRF Version 4; Technical Report; NCAR; NCAR Tech. Note NCAR/TN-556+STR; National Center for Atmospheric Research: Boulder, CO, USA, 2019; p. 145. [CrossRef]

6. Courtier, P.; Geleyn, J.F. A global numerical weather prediction model with variable resolution: Application to the shallow model equations. Q. J. R. Meteorol. Soc. 1988, 114, 1321-1346. [CrossRef]

7. Walters, D.; Baran, A.J.; Boutle, I.; Brooks, M.; Earnshaw, P.; Edwards, J.; Furtado, K.; Hill, P.; Lock, A.; Manners, J.; et al. The Met Office Unified Model Global Atmosphere 7.0/7.1 and JULES Global Land 7.0 configurations. Geosci. Model Devel. 2019, 12, 1909-1963. [CrossRef]

8. Sela, J. Implementation of the sigma pressure hybrid coordinate into GFS. NCEP Off. Note 2009, 461, 1-25.

9. ECMWF. IFS Documentation CY47R1; Technical Report; ECMWF: Reading, UK, 2020.

10. Maidment, R.I.; Grimes, D.I.F.; Black, E.; Tarnavsky, E.; Young, M.; Greatrex, H.; Allan, R.P.; Stein, T.H.M.; Nkonde, E.; Senkunda, S.; et al. A new, long-term daily satellite-based rainfall dataset for operational monitoring in Africa. Nat. Sci. Data 2017, 4, 170063. [CrossRef] [PubMed] 
11. World Meteorological Organization (WMO). Commission for Basic Systems Severe Weather Forecasting Demonstration Project (SWFDP): The Overall Project Plan; Technical Report; WMO: Geneva, Switzerland, 2010.

12. World Meteorological Organization (WMO). World Weather Information Service: Official Forecasts; WMO: Geneva, Switzerland, 2020; Volume 49, pp. 59-71.

13. Bauer, P.; Thorpe, A.; Brunet, G. The quiet revolution of numerical weather prediction. Nature 2015, 525, 47-55. [CrossRef]

14. Carr, H. Atos Supercomputer to Enhance Weather Prediction Capabilities for Leading European Numerical Weather Centre ECMWF; ECMWF: Reading, UK, 2020; pp. 1-3.

15. Met Office Press Office. Up to £1.2 Billion for Weather and Climate Supercomputer; Met Office: Devon, UK, 2020.

16. Motshegwa, T.; Wright, C.; Sithole, H.; Ngolwe, C.; Morgan, A. Developing a Cyber-infrastructure for Enhancing Regional Collaboration on Education, Research, Science, Technology and Innovation. In Proceedings of the 2018 IST-Africa Week Conference (IST-Africa), Gaborone, Botswana, 9-11 May 2018; pp. 1-9.

17. Bopape, M.M.; Sithole, H.; Motshegwa, T.; Rakate, E.; Engelbrecht, F.; Morgan, A.; Ndimeni, L.; Botai, O.J. A Regional Project in Support of the SADC Cyber-Infrastructure Framework Implementation: Weather and Climate. Data Sci. J. 2019, 18, 34. [CrossRef]

18. Kanno, H.; Sakurai, T.; Shinjo, H.; Miyazaki, H.; Ishimoto, Y.; Saeki, T.; UMETSU, C. Analysis of Meteorological Measurements made over Three Rainy Seasons and Rainfall Simulations in Sinazongwe District, Southern Province, Zambia. Jpn. Agric. Res. Q. 2015, 49, 59-71. [CrossRef]

19. Stensrud, D. Parameterization Schemes: Keys to Understanding Numerical Weather Prediction Models; Reprint of the 2007 hardback ed.; Cambridge University Press: Cambridge, UK, 2007; p. 480. [CrossRef]

20. Stull, R.B. An Introduction to Boundary Layer Meteorology; Kluwer Academic Publishers: Dordrecht, The Netherlands, $1988 ;$ p. 666.

21. Houze, R.A.J. Cloud Dynamics; Academic Press: San Diego, CA, USA, 1994; p. 573.

22. Deardorff, J.W. Parameterization of the planetary boundary layer for use in general circulation models. Mon. Weather. Rev. 1974, 100, 93-106. [CrossRef]

23. Qian, Y.; Yan, H.; Berg, L.K.; Hagos, S.; Feng, Z.; Yang, B.; Huang, M. Assessing Impacts of PBL and Surface Layer Schemes in Simulating the Surface-Atmosphere Interactions and Precipitation over the Tropical Ocean Using Observations from AMIE/DYNAMO. J. Clim. 2016, 29, 8191-8210. [CrossRef]

24. Jahn, D.; Gallus, W. Impacts of Modifications to a Local Planetary Boundary Layer Scheme on Forecasts of the Great Plains Low-Level Jet Environment. Weather. Forecast. 2018, 33, 1109-1120. [CrossRef]

25. Hong, S.Y.; Noh, Y.; Dudhia, J. A New Vertical Diffusion Package with an Explicit Treatment of Entrainment Processes. Mon. Weather. Rev. 2006, 134, 2318-2341. [CrossRef]

26. Nakanishi, M.; Niino, H. Development of an Improved Turbulence Closure Model for the Atmospheric Boundary Layer. J. Meteorol. Soc. Jpn. 2009, 87, 895-912. [CrossRef]

27. Bélair, S.; Mailhot, J.; Strapp, J.W.; MacPherson, J.I. An Examination of Local versus Nonlocal Aspects of a TKE-Based Boundary Layer Scheme in Clear Convective Conditions. J. Appl. Meteorol. 1999, 38, 1499-1518. [CrossRef]

28. Cohen, A.E.; Cavallo, S.M.; Coniglio, M.C.; Brooks, H.E.; Jirak, I.L. Evaluation of Multiple Planetary Boundary Layer Parameterization Schemes in Southeast U.S. Cold Season Severe Thunderstorm Environments. Weather. Forecast. 2017, 32, 1857-1884. [CrossRef]

29. Comin, A.; Justino, F.; Pezzi, L.; Gurjão, C.; Schumacher, V.; Fernández, A.; Sutil, U. Extreme rainfall event in the Northeast coast of Brazil: A numerical sensitivity study. Meteorol. Atmos. Phys. 2020. [CrossRef]

30. Hu, X.M.; Nielsen-Gammon, J.W.; Zhang, F. Evaluation of Three Planetary Boundary Layer Schemes in the WRF Model. J. Appl. Meteorol. Climatol. 2010, 49, 1831-1844. [CrossRef]

31. de Lange, A.; Naidoo, M.; Garland, R.; Dyson, L. Sensitivity of meteorological variables on planetary boundary layer parameterization schemes in the WRF-ARW model. Atmos. Res. 2021, 247, 105214. [CrossRef]

32. Libanda, B.; Ogwang, B.; Ongoma, V.; Ngonga, C.; Nyasa, L. Diagnosis of the 2010 DJF flood over Zambia. Nat. Hazards 2016, 81, 189-2016 [CrossRef]

33. Hachigonta, S.; Reason, C. Interannual variability in dry and wet spell characteristics over Zambia. Clim. Res. 2006, 32, 49-62. [CrossRef]

34. Thurlow, J.; Zhu, T.; Diao, X. The Impact of Climate Variability and Change on Economic Growth and Poverty in Zambia; IFPRI Discussion Papers; International Food Policy Research Institute (IFPRI): Washington, DC, USA, 2009.

35. Nyambe, S.; Gomes, C.; Lubasi, F.; Gomes, A. Analysis of Lightning Occurence in Zambia. In Proceedings of the 2014 International Conference on Lightning Protection (ICLP), Shanghai, China, 11-18 October 2014; pp. 1919-1925. [CrossRef]

36. Libanda, B.; Nkolola, N.; Bathsheba, M. Rainfall Variability over Northern Zambia. J. Sci. Res. Rep. 2015, 6, 416-425. [CrossRef]

37. del Ninno, C.; Marini, A. Household's vulnerability to shocks in Zambia. Soc. Prot. Discuss. Pap. World Bank 2005, $526,43$.

38. Luque-Fernandez, M.; Bauernfeind, A.; Díaz, J.; Linares, C.; Omeiri, N.; Guibert, D. Influence of temperature and rainfall on the evolution of cholera epidemics in Lusaka, Zambia, 2003-2006: Analysis of a time series. Trans. R. Soc. Trop. Med. Hyg. 2008, 103, 137-143. [CrossRef] [PubMed]

39. Chinowsky, P.; Schweikert, A.; Strzepek, N.; Strzepek, K. Infrastructure and climate change: A study of impacts and adaptations in Malawi, Mozambique, and Zambia. Clim. Chang. 2015, 130, 49-62. [CrossRef]

40. Thurlow, J.; Diao, X. Current Climate Variability and Future Climate Change: Estimated Growth and Poverty Impacts for Zambia. Rev. Dev. Econ. 2012, 16, 394-411. [CrossRef] 
41. Clark, P.; Roberts, N.; Lean, H.; Ballard, S.; Charlton-Perez, C. Convection-permitting models: A step-change in rainfall forecasting. Meteorol. Appl. 2016, 23, 165-181. [CrossRef]

42. Wang, W. WRF: More Runtime Options. In WRF Tutorial; UNSW: Sydney, NSW, Australia, 2017; p. 46.

43. Sun, B.Y.; Bi, X. Validation for a tropical belt version of WRF: Sensitivity tests on radiation and cumulus convection parameterizations. Atmos. Ocean. Sci. Lett. 2019, 12, 192-200. [CrossRef]

44. Iacono, M.; Delamere, J.; Mlawer, E.; Shepard, M.; Clough, S.; Collins, W. Radiative Forcing by Long-Lived Greenhouse Gases: Calculations with the AER Radiative Transfer Models. J. Geophys. Res. 2008, 113. [CrossRef]

45. Hong, S.Y.; Kim, J.H.; Lim, J.O.; Dudhia, J. The WRF single moment microphysics scheme (WSM). J. Korean Meteorol. Soc. 2006, 42, 129-151.

46. Tiedtke, M.A. A Comprehensive Mass Flux Scheme For Cumulus Parameterization In Large-Scale Models. Mon. Weather. Rev. 1989, 117, 1779-1800. [CrossRef]

47. Zhang, C.; Wang, Y.; Hamilton, K. Improved Representation of Boundary Layer Clouds over the Southeast Pacific in ARW-WRF Using a Modified Tiedtke Cumulus Parameterization Scheme. Mon. Weather Rev. 2011, 139, 3489-3513. [CrossRef]

48. Zhang, S.; Matsui, T.; Cheung, S.; Zupanski, M.; Peters-Lidard, C. Impact of Assimilated Precipitation-Sensitive Radiances on the NU-WRF Simulation of the West African Monsoon. Mon. Weather Rev. 2017, 145, 3881-3900. [CrossRef]

49. Holtslag, A.A.M.; Boville, B.A. Local Versus Nonlocal Boundary-Layer Diffusion in a Global Climate Model. J. Clim. 1993, 6, 1825-1842. [CrossRef]

50. Bretherton, C.S.; Park, S. A New Moist Turbulence Parameterization in the Community Atmosphere Model. J. Clim. 2009, 22, 3422-3448. [CrossRef]

51. Hong, S.Y.; Pan, H.L. Nonlocal Boundary Layer Vertical Diffusion in a Medium-Range Forecast Model. Mon. Weather Rev. 1996, 124, 2322-2339. [CrossRef]

52. Lean, H.W.; Clark, P.A.; Dixon, M.; Roberts, N.M.; Fitch, A.; Forbes, R.; Halliwell, C. Characteristics of High-Resolution Versions of the Met Office Unified Model for Forecasting Convection over the United Kingdom. Mon. Weather Rev. 2008, 136, 3408-3424. [CrossRef]

53. Kain, J.S.; Weiss, S.J.; Levit, J.J.; Baldwin, M.E.; Bright, D.R. Examination of convection-allowing configurations of the WRF model for the prediction of severe convective weather: The SPC/NSSL Spring Program 2004. Wea. Forecast. 2006, 21, 167-181. [CrossRef]

54. Crook, J.; Klein, C.; Folwell, S.; Taylor, C.M.; Parker, D.J.; Stratton, R.; Stein, T. Assessment of the Representation of West African Storm Lifecycles in Convection-Permitting Simulations. Earth Space Sci. 2019, 6, 818-835. [CrossRef]

55. Tarnavsky, E.; Grimes, D.; Maidment, R.; Black, E.; Allan, R.; Stringer, M.; Chadwick, R.; Kayitakire, F. Extension of the TAMSAT Satellite-Based Rainfall Monitoring over Africa and from 1983 to Present. J. Appl. Meteorol. Clim. 2014, 53, 2805-2822. [CrossRef]

56. Huffman, G.; Bolvin, D.; Braithwaite, D.; Hsu, K.; Joyce, R.; Xie, P. NASA Global Precipitation Measurement Integrated Multi-Satellite Retrievals for GPM (IMERG); Algorithm Theoretical Basis Doc., Version 4.4; NASA's Precipitation Processing Center; NASA: Washington, DC, USA, 2014; Volume 5, 30p.

57. Hersbach, H.; Dee, D. ERA5 Reanalysis Is in Production; ECMWF: Reading, UK, 2016; p. 147.

58. Davis, C.; Brown, B.; Bullock, R. Object-Based Verification of Precipitation Forecasts. Part I: Methodology and Application to Mesoscale Rain Areas. Mon. Weather. Rev. 2006, 134, 1772-1784. [CrossRef]

59. Davis, C.; Brown, B.; Bullock, R. Object-Based Verification of Precipitation Forecasts. Part II: Application to Convective Rain Systems. Mon. Weather. Rev. 2006, 134, 1785-1795. [CrossRef]

60. Brown, B.; Bullock, R.; Gotway, J.; Ahijevch, D.; Davis, C.; Gilleland, E.; Holland, L. Application of the MODE object-based verification tool for the evaluation of model precipitation fields. In Proceedings of the 22nd Conference on Weather Analysis and Forecasting/18th Conference on Numerical Weather Prediction, Park City, UT, USA, 25 June 2007.

61. Beusch, L.; Foresti, L.; Gabella, M.; Hamann, U. Satellite-Based Rainfall Retrieval: From Generalized Linear Models to Artificial Neural Networks. Remote. Sens. 2018, 10, 939. [CrossRef]

62. Kerns, B.; Chen, S. ECMWF and GFS model forecast verification during DYNAMO: Multiscale variability in MJO initiation over the equatorial Indian Ocean. J. Geophys. Res. Atmos. 2014, 119, 3736-3755. [CrossRef]

63. Dias, J.; Gehne, M.; Kiladis, G.; Sakaeda, N.; Bechtold, P.; Haiden, T. Equatorial Waves and the Skill of NCEP and ECMWF Numerical Weather Prediction Systems. Mon. Weather. Rev. 2018, 146, 1763-1784. [CrossRef]

64. Molongwane, C.; Bopape, M.J.; Fridlind, A.; Motshegwa, T.; Matsui, T.; Phaduli, E.; Sehurutshi, B.; Maisha, R. Sensitivity of Botswana Ex-Tropical Cyclone Dineo rainfall simulations to cloud microphysics scheme. AAS Open Res. 2020, 3, 30. [CrossRef]

65. Ndarana, T.; Rammopo Tsholanang, S.; Chikoore, H.; Barnes, M.A.; Bopape, M.J. A quasi-geostrophic diagnosis of the zonal flow associated with cut-off lows over South Africa and surrounding oceans. Clim. Dyn. 2020, 55, 2631-2644. [CrossRef]

66. Somses, S.; Bopape, M.J.M.; Ndarana, T.; Fridlind, A.; Matsui, T.; Phaduli, E.; Limbo, A.; Maikhudumu, S.; Maisha, R.; Rakate, E. Convection parametrization and multi-nesting dependence of a heavy rainfall event over Namibia with Weather Research and Forecasting (WRF) model. Climate 2020, 8, 112. [CrossRef]

67. Thorne, V.; Coakeley, P.; Grimes, D.; Dugdale, G. Comparison of TAMSAT and CPC Rainfall Estimates with rainfall, for southern Africa. Int. J. Remote Sens. 2001, 22, 1951-1974. [CrossRef]

68. Syama, S.; Masocha, M.; Dube, T. Evaluation of TAMSAT satellite rainfall estimates for southern Africa: An inter-product comparison study. Phys. Chem. Earth Parts A/B/C 2019, 112, 141-153. [CrossRef] 
69. Beck, H.; Pan, M.; Roy, T.; Weedon, G.; Pappenberger, F.; van Dijk, A.; Huffman, G.; Adler, R.; Wood, E. Daily evaluation of 26 precipitation datasets using Stage-IV gauge-radar data for the CONUS. Hydrol. Earth Syst. Sci. 2019, 23, 207-224. [CrossRef]

70. Bopape, M.J.; Engelbrecht, F.; Randall, D.; Landman, W. Simulations of an isolated two-dimensional thunderstorm: Sensitivity to cloud droplet size and the presence of graupel. Asia-Pac. J. Atmos. Sci. 2014, 50, 139-151. [CrossRef]

71. Champion, A.; Hodges, K. Importance of resolution and model configuration when downscaling extreme precipitation. Tellus $A$ 2014, 66. [CrossRef]

72. Medeiros, B.; Hall, A.; Stevens, B. What controls the mean depth of the PBL? Earth Space Sci. 2005, 18, 3157-3172. [CrossRef]

73. Efstathiou, G.A.; Plant, R.S.; Bopape, M.J.M. Simulation of an Evolving Convective Boundary Layer Using a Scale-Dependent Dynamic Smagorinsky Model at Near-Gray-Zone Resolutions. J. Appl. Meteorol. Clim. 2018, 57, 2197-2214. [CrossRef]

74. Bopape, M.J.; Plant, R.; Coceal, O.; Efstathiou, G.; Valdivieso, M. Effects of stability functions in a dynamic model convective boundary layer simulation. Atmos. Sci. Lett. 2021, 22, e1008. [CrossRef]

75. Steeneveld, G.J.; Peerlings, E. Mesoscale Model Simulation of a Severe Summer Thunderstorm in The Netherlands: Performance and Uncertainty Assessment for Parameterised and Resolved Convection. Atmosphere 2020, 11, 811. [CrossRef]

76. Cintineo, R.; Otkin, J.A.; Xue, M.; Kong, F. Evaluating the Performance of Planetary Boundary Layer and Cloud Microphysical Parameterization Schemes in Convection-Permitting Ensemble Forecasts Using Synthetic GOES-13 Satellite Observations. Mon. Weather. Rev. 2014, 142, 163-182. [CrossRef] 